\title{
Breeding response of transcript profiling in developing seeds of
} Brassica napus

\author{
Yaping $\mathrm{Hu}$, Gang Wu, Yinglong Cao, Yuhua Wu, Ling Xiao, Xiaodan Li and \\ Changming Lu*
}

Address: Oil Crops Research Institute, Chinese Academy of Agricultural Sciences, No. 2 Xudong 2nd Road, Wuhan, 430062, PR China

Email: Yaping Hu - huyaping_1981@yahoo.com.cn; Gang Wu - wugang1976@gmail.com; Yinglong Cao - caoyinglong@sina.com; Yuhua Wu - wuyuhua@oilcrops.cn; Ling Xiao - xiaoling@oilcrops.cn; Xiaodan Li - lxiaodan@163.com; Changming Lu* - cmlu@oilcrops.cn

* Corresponding author

\section{Published: 24 May 2009}

BMC Molecular Biology 2009, 10:49 doi:10.1186/1471-2199-10-49
Received: 20 October 2008

Accepted: 24 May 2009

This article is available from: http://www.biomedcentral.com/I47/-2/99//0/49

(c) 2009 Hu et al; licensee BioMed Central Ltd.

This is an Open Access article distributed under the terms of the Creative Commons Attribution License (http://creativecommons.org/licenses/by/2.0), which permits unrestricted use, distribution, and reproduction in any medium, provided the original work is properly cited.

\begin{abstract}
Background: The upgrading of rapeseed cultivars has resulted in a substantial improvement in yield and quality in China over the past 30 years. With the selective pressure against fatty acid composition and oil content, high erucic acid- and low oil-content cultivars have been replaced by low erucic acid- and high oil-content cultivars. The high erucic acid cultivar Zhongyou $82 \mathrm{I}$ and its descendent, low erucic acid cultivar Zhongshuang 9, are representatives of two generations of the most outstanding Chinese rapeseed cultivars (B. napus) developed the past 2 decades. This paper compares the transcriptional profiles of Zhongshuang 9 and Zhongyou 821 for 32 genes that are principally involved in lipid biosynthesis during seed development in order to elucidate how the transcriptional profiles of these genes responded to quality improvement over the past 20 years.
\end{abstract}

Results: Comparison of the cultivar Zhongyou 821 with its descendent, Zhongshuang 9, shows that the transcriptional levels of seven of the 32 genes were upregulated by $30 \%$ to $109 \%$, including FAD3, ACCase, FAEI, GKTP, Caleosin, GAPDH, and PEPC. Of the 32 genes, 10 (KAS3, $\beta$-CT, BCRK6, $P 450$, FatA, Oleosin, FAD6, FatB, $\alpha-C T$ and $S U C I$ ) were downregulated by at least $20 \%$ and most by $50 \%$. The Napin gene alone accounted for over $75 \%$ of total transcription from all 32 genes assessed in both cultivars. Most of the genes showed significant correlation with fatty acid accumulation, but the correlation in ZS9 was significantly different from that in ZY82I. Higher KCR2 activity is associated with higher $\mathrm{Cl}$ 6:0, Cl8:0, and Cl8:2 in both cultivars, lower C22:I and total fatty acid content in ZY82I, and lower I8:I in ZS9.

Conclusion: This paper illustrates the response of the transcription levels of 32 genes to breeding in developing rapeseed seeds. Both cultivars showed similar transcription profiles, with the Napin gene predominantly transcribed. Selective pressure for zero erucic acid, low glucosinolate, high oleic acid and high oil content, as well as high yield, resulted in higher FAD3, ACCase, FAEI, GKTP, Caleosin, GAPDH, and PEPC expression levels and lower KAS3, $\beta-C T$, BCRK6, P450, FatA, Oleosin, FAD6, FatB, $\alpha-C T$ and $S U C l$ expression levels. It also resulted in altered relationships between these genes during storage accumulation in seed development. 


\section{Background}

Rapeseed (Brassica napus L.) is one of the most important oil crops in the world. The annual planting acreage is about $8 \mathrm{MH}$ (million hectare) in China, which accounts for a quarter of the world's total rapeseed production. Over the past 30 years, with the rape cultivar upgrades, China's rapeseed production has experienced tremendous advancement. The substantial improvement in yield and quality has greatly expanded the cultivation area and improved production efficiency in China.

Before 1990, almost all rapeseed cultivars in China were high in erucic acid and glucosinolate levels (double-high). Zhongyou 821 (abbrev. ZY821) dominated rapeseed planting along the middle and lower reaches of the Yangtze River at that time, with an annual planting area of around $1.8 \mathrm{MH}$ in the late 1980s and early 1990s. With intense breeding toward high oil content and double low quality (low erucic acid and low-glucosinolate levels), Zhongshuang 9 (abbrev. ZS9), bred using ZY821 as one of the crossing parents, was released in 2002. Due to better comprehensive agronomic characteristics, ZS9 has rapidly replaced ZY821 and become one of the most popular double-low rapeseed cultivars in China. From 2003 to 2007, the total planting acreage of ZS9 was in excess of $0.47 \mathrm{MH}$. ZS9 is characterized by a $2.2 \%$ higher oil content, $51.1 \%$ higher oleic acid content, $43.4 \%$ lower erucic acid content and $8.6 \%$ lower eicosenoic acid content than ZY821 (Table 1). The double high cultivar ZY821 and the double low cultivar ZS9 have been two of the most popular rapeseed cultivars in China, representing two generations of Chinese rapeseed cultivars and reflecting the major achievements in rapeseed quality improvement over the past 30 years.

Significant improvements in oil quality must be accompanied by changes in gene activities involving fatty acid biosynthesis in developing seeds. The elucidation of gene transcription patterns associated with a specific stage of seed development is critical for understanding the molec- ular and biochemical events related to oilseed quality improvement. Characterization of these genes and their regulatory elements would provide not only new genetic information for understanding $B$. napus seed development, but also alternative seed promoters for controlling gene expression in developing seeds. Liu et al. analyzed the proteomic pattern and the gene transcripts of early germs with high-oil content and normal inbred lines in maize and found that three enzymes involved in lipid metabolism, namely, putative enoyl-ACP reductase $(E N R)$, putative stearoyl-ACP desaturase (SAD) and putative Acetyl-CoA carboxylase (ACCase), had more abundant expression in high-oil lines than in the normal lines [1]. High expression of SAD, ENR and ACCase was associated with increasing oil concentration in high-oil maize. Dong et al. described the tissue-specific expression of 54 highly expressed mRNAs during early stages of seed development in B. napus and found that the majority of the seed-specific genes that are expressed at early stages of seed development encoded proteins with high similarity to hypothetical Arabidopsis proteins [2]. Genes in various metabolic and storage pathways exhibit distinct timing patterns, indicating that different sets of transcriptional factors turn on oil and protein pathway genes [3-5]. Knowledge of the expression of multiple genes and their regulation during oil biosynthesis is needed to further understand the regulatory mechanisms controlling oil metabolism [6]. This understanding will aid in the development of suitable tools for altering seed development and seed quality traits by molecular genetics.

Rapeseed seed quality in China has been drastically improved under selective pressure against fatty acid composition and oil content, but no reports have been made on the associated changes in related gene activities. In this study, we investigate how the transcriptional profiles of genes involved in fatty acid biosynthesis respond to the selective pressures against oil content and fatty acid composition and how the genes coordinate with each other. Our results provide a first glimpse of the gene expression

Table I: Difference between ZY82I and ZS9.

\begin{tabular}{|c|c|c|c|}
\hline & ZY82I & ZS9 & Difference \\
\hline Yield (kg/ha) & 9.57 & 11.03 & \\
\hline Protein content (\%) & $31.27 \%$ & $32.83 \%$ & $1.56 \% *$ \\
\hline Oil content(\%) & $39.80 \%$ & $42.00 \%$ & $2.20 \% * *$ \\
\hline Glucosinolate content in meal $(\mu \mathrm{m} / \mathrm{g})$ & 123.50 & 19.18 & $-104.32 * *$ \\
\hline Erucic acid (\%) & $42.00 \%$ & $0.23 \%$ & $-45.77 \% * *$ \\
\hline Eicosenoic acid (\%) & $9.75 \%$ & $1.20 \%$ & $-8.55 \% * *$ \\
\hline Oleic acid & $16.90 \%$ & $68.00 \%$ & $51.10 \% * *$ \\
\hline Duration of dominating cultivation & $1988-1995$ & 2003-Now & \\
\hline Average annual coverage & I.80 MH & $0.47 \mathrm{MH}$ & \\
\hline
\end{tabular}

*means different character, ${ }^{*}$ means larger different character. 
and regulation breeding response to selective pressures in rapeseed, which is critical to metabolic engineering and the quality improvement of oilseeds.

\section{Results}

Seed Development and Fatty Acid Accumulation Patterns During the first few weeks of seed development, the seed coat expanded until the seed was almost full size. At this stage, the seed was somewhat translucent and resembled a water-filled balloon. It was difficult to dissect ovules from the pod at $5 \mathrm{DAP}$ (days after pollination) but it became possible after 10 DAP. The seed's embryo now began development and grew rapidly within the seed coat to fill the space previously occupied by fluid. The mature seed was harvested at 45 DAP.

In the ZS9 cultivar, the total fatty acid content continued to increase and peaked at about $40 \mathrm{DAP}$, followed by a gentle drop with seed maturation (Fig. 1A). In contrast, ZY821 showed a similar pattern of accumulation of total fatty acids except that it had higher levels at 30 DAP (Fig. 1A). Nine fatty acids were found in ZY821 (Fig. 1B-J) but only five in ZS9 (Fig. 1B-F). Among the five common fatty acids, only oleic acid (C18:1) showed different accumula-
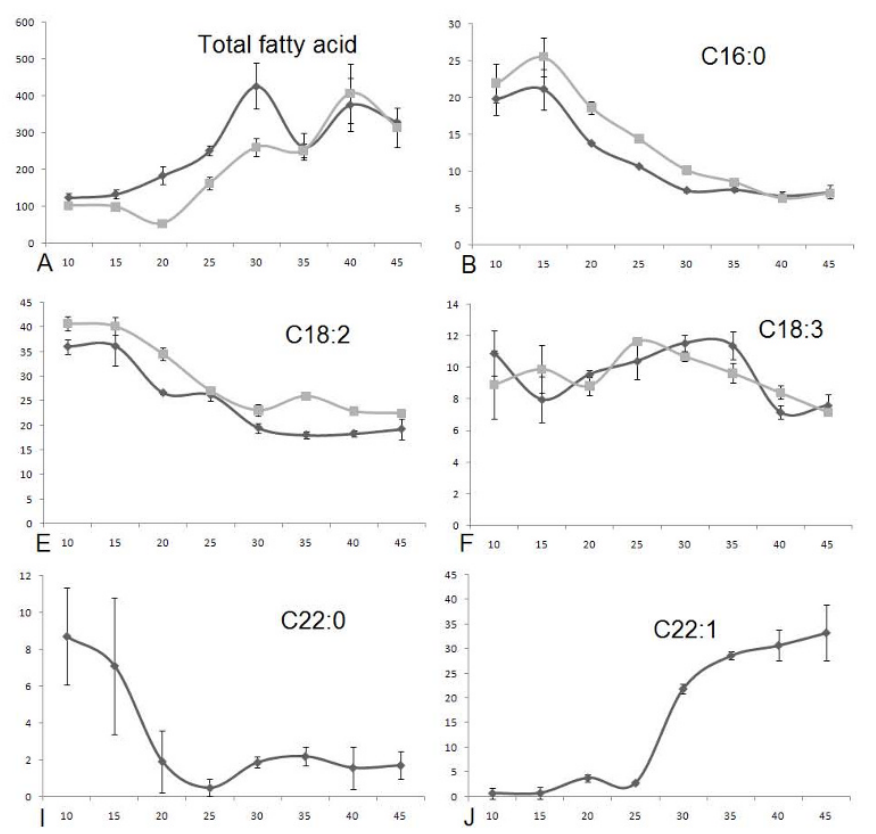

tion patterns (Fig. 1D), whereas the other fatty acids accumulated in similar patterns in both cultivars (Fig. 1B-F). In ZS9, the oleic acid content increased continuously and became a major component at the end (Fig. 1D), whereas in ZY821, oleic acid ascended in the early stages (10-25 DAP) but decreased from 25 DAP to 35 DAP and then remained constant until the end (Fig. 1D). The initial content of all saturated fatty acids (C16:0, C18:0, C20:0 and C22:0) was relatively high but decreased from 15 DAP and reached a minimum at about 25-30 DAP, ultimately comprising a minor proportion of the fatty acids in mature seeds (Fig. 1B, C, G, I). The content of C18:2 was as high as $35-42 \%$ during the initial stages (10-15 DAP) and decreased continuously to a final content of about $20 \%$ (Fig. 1E). The C18:3 content fluctuated from $6 \%$ to $11.4 \%$ and was fixed at about $7 \%$ in mature seeds (Fig. $1 \mathrm{~F})$.

\section{Relative Transcript Levels for the 32 Genes}

Different genes had different transcript levels but with very similar tendencies between the two cultivars in general (Table 2 and Fig. 2). In both cultivars, ZY821 and ZS9, the top 7 genes, including Napin, Oleosin, $\beta-C T$, Caleosin, $\beta$-actin, FAE1 and Cruciferin, accounted for over $95 \%$ of
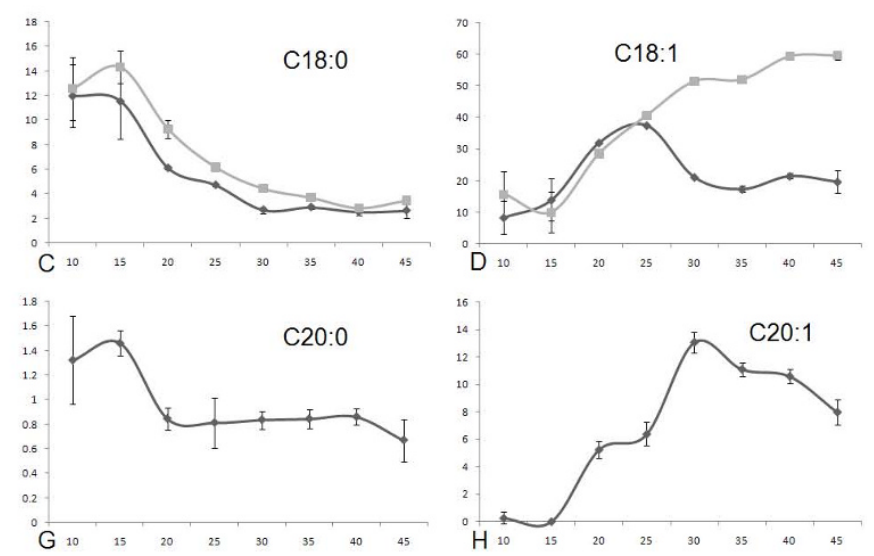

$$
\rightarrow \text { ZY821 }
$$$$
- \text { ZS9 }
$$

\section{Figure I}

Fatty acid accumulation patterns in seed development. (A) The trend of total fatty acid accumulation in seed development. Fatty acids peaked at different times but the end accumulation was similar. (B-J) The accumulation pattern of fatty acids present in both cultivars. Most share similar accumulation patterns, but CI8:I was quite different between the two cultivars. Values in parentheses indicate the relative composition percentage and values in abscissa indicate the seed development stage. The black curves represent ZY82I and the gray curves represent ZS9. Each data point represents the mean \pm SD of three replicates. 
Table 2: Characterization of transcript profiles in developing seeds of $B$. napus.

\begin{tabular}{|c|c|c|c|c|c|c|c|c|c|c|c|c|}
\hline \multirow[t]{2}{*}{ Rank } & \multirow[t]{2}{*}{$\begin{array}{l}\text { Gene } \\
\text { name }\end{array}$} & \multicolumn{2}{|c|}{$\begin{array}{c}\text { Mean transcript level } \\
(\mathrm{TL})\end{array}$} & \multirow{2}{*}{$\begin{array}{r}\text { Ratio of } \\
\text { Mean TL } \\
\text { ZS9/ } \\
\text { ZY82I }\end{array}$} & \multicolumn{2}{|c|}{$\begin{array}{l}\text { Relative transcript level } \\
\text { (RTL)(\%) }\end{array}$} & \multicolumn{2}{|c|}{$\begin{array}{l}\text { Coefficient of variation } \\
\text { (\%) }\end{array}$} & \multicolumn{2}{|c|}{ Peak value } & \multicolumn{2}{|c|}{ Day of peak(DAP) } \\
\hline & & ZS9 & ZY82I & & ZS9 & ZY82I & ZS9 & ZY82I & ZS9 & $\underset{1}{Z Y 82}$ & ZS9 & ZY82I \\
\hline I & Napin & 46.92 & 50.22 & 0.93 & 76.89 & $75.4 I$ & 156.10 & 140.02 & 178.46 & 172.97 & 35.00 & 45.00 \\
\hline 2 & Oleosin & 3.91 & 5.47 & 0.71 & 6.40 & 8.21 & 133.12 & 167.69 & 13.50 & 23.93 & 40.00 & 40.00 \\
\hline 3 & $\beta-C T$ & 2.98 & 4.68 & 0.64 & 4.89 & 7.03 & $|12.9|$ & 79.70 & 10.32 & 11.50 & 15.00 & 15.00 \\
\hline 4 & Caleosin & $\mathrm{I} .43$ & 0.89 & 1.60 & 2.34 & 1.34 & 138.14 & 134.30 & 5.09 & 3.10 & 40.00 & 40.00 \\
\hline 5 & FAEI & 1.09 & 0.60 & 1.80 & 1.78 & 0.91 & 103.81 & 110.91 & 3.30 & 2.06 & 30.00 & 40.00 \\
\hline 6 & $\beta$-Actin & 1.00 & 1.00 & 1.00 & 1.64 & 1.50 & 40.57 & 46.89 & 1.69 & 1.56 & 45.00 & 40.00 \\
\hline 7 & Cruciferin & 0.99 & 1.17 & 0.85 & 1.62 & 1.76 & 172.95 & 147.58 & 4.99 & 4.30 & 40.00 & 45.00 \\
\hline 8 & $S A D$ & 0.45 & 0.53 & 0.84 & 0.74 & 0.80 & 97.89 & 95.50 & 1.35 & 1.71 & 25.00 & 25.00 \\
\hline 9 & GAPDH & 0.39 & 0.42 & 0.93 & 0.64 & 0.63 & 78.85 & 80.08 & 1.26 & 0.75 & 20.00 & 15.00 \\
\hline 10 & GKTP & 0.38 & 0.23 & 1.66 & 0.62 & 0.34 & 138.40 & 38.09 & 1.64 & 0.38 & 45.00 & 45.00 \\
\hline 11 & KCR2 & 0.18 & 0.16 & 1.07 & 0.29 & 0.25 & 38.04 & 55.82 & 0.29 & 0.35 & 10.00 & 15.00 \\
\hline 12 & FAD3 & 0.17 & 0.08 & 2.09 & 0.28 & 0.12 & 79.09 & 61.19 & 0.38 & 0.15 & 25.00 & 30.00 \\
\hline 13 & ACCase & 0.16 & 0.08 & 2.05 & 0.26 & 0.12 & 70.26 & 13.27 & 0.38 & 0.10 & 30.00 & 35.00 \\
\hline 14 & FAD2 & 0.16 & 0.14 & 1.09 & 0.26 & 0.22 & 65.42 & 80.85 & 0.35 & 0.42 & 25.00 & 25.00 \\
\hline 15 & $B c R K 6$ & 0.15 & 0.22 & 0.65 & 0.24 & 0.34 & 122.44 & 103.15 & 0.44 & 0.60 & 15.00 & 20.00 \\
\hline 16 & KASI & 0.14 & 0.12 & 1.23 & 0.23 & 0.17 & 87.64 & 56.55 & 0.40 & 0.24 & 30.00 & 25.00 \\
\hline 17 & $B C$ & 0.10 & 0.09 & 1.13 & 0.17 & 0.14 & 46.83 & 47.12 & 0.17 & 0.14 & 10.00 & 10.00 \\
\hline 18 & AGPase & 0.06 & 0.05 & 1.06 & 0.10 & 0.08 & 74.79 & 55.15 & 0.15 & 0.10 & 25.00 & 15.00 \\
\hline 19 & KAS2 & 0.05 & 0.04 & 1.13 & 0.08 & 0.06 & 74.76 & 57.42 & 0.12 & 0.08 & 10.00 & 10.00 \\
\hline 20 & FAD6 & 0.05 & 0.06 & 0.75 & 0.08 & 0.09 & 86.72 & 65.94 & 0.11 & 0.10 & 15.00 & 15.00 \\
\hline 21 & PEPC & 0.04 & 0.03 & 1.39 & 0.06 & 0.04 & 61.29 & 62.14 & 0.07 & 0.05 & 10.00 & 15.00 \\
\hline 22 & LPAAT & 0.04 & 0.03 & 1.22 & 0.06 & 0.04 & 54.31 & 55.81 & 0.06 & 0.05 & 25.00 & 15.00 \\
\hline 23 & FatA & 0.03 & 0.05 & 0.68 & 0.05 & 0.07 & 65.09 & 71.64 & 0.07 & 0.10 & 15.00 & 10.00 \\
\hline 24 & $K A C D$ & 0.03 & 0.03 & 1.24 & 0.05 & 0.04 & 64.80 & 50.96 & 0.06 & 0.04 & 10.00 & 10.00 \\
\hline 25 & DGAT2 & 0.03 & 0.04 & 0.86 & 0.05 & 0.05 & 47.42 & 50.37 & 0.06 & 0.06 & 15.00 & 15.00 \\
\hline 26 & SUCI & 0.02 & 0.03 & 0.80 & 0.04 & 0.05 & 121.95 & 93.63 & 0.08 & 0.07 & 10.00 & 20.00 \\
\hline 27 & $\alpha-C T$ & 0.02 & 0.03 & 0.78 & 0.04 & 0.04 & 50.17 & 57.06 & 0.04 & 0.05 & 20.00 & 20.00 \\
\hline 28 & P450 & 0.02 & 0.03 & 0.66 & 0.03 & 0.04 & 142.86 & 109.94 & 0.06 & 0.08 & 10.00 & 10.00 \\
\hline 29 & FatB & 0.02 & 0.02 & 0.78 & 0.03 & 0.03 & 108.45 & 86.96 & 0.05 & 0.04 & 10.00 & 10.00 \\
\hline 30 & KAS3 & 0.01 & 0.03 & 0.49 & 0.02 & 0.05 & 119.26 & 109.93 & 0.05 & 0.09 & 15.00 & 20.00 \\
\hline 31 & MCAT & 0.01 & 0.01 & 1.22 & 0.02 & 0.01 & 106.77 & 107.48 & 0.03 & 0.02 & 20.00 & 25.00 \\
\hline 32 & AAPTI & 0.01 & 0.01 & 0.88 & 0.01 & 0.01 & 106.59 & 216.06 & 0.01 & 0.04 & 15.00 & 10.00 \\
\hline
\end{tabular}

TL means mean transcript level, C.V. of TL means coefficient of variation of transcript level, and RTL means relative value of the transcript levels, DAP means days after pollination, or days between the pollination and the transcript peak occuring.

the transcript levels from the 32 genes (Table 2). The genes coding for storage proteins alone accounted for $87 \%$, of which the Napin transcript was $77 \sim 78 \%$ of the total, Oleosin 6 8\%, and Caleosin and Cruciferin about $1 \sim 2 \%$. For other non-storage protein genes, $\beta-C T$, GAPDH, FAE1 and SAD showed relatively higher transcript levels and accounted for $11 \%$ of the total transcripts (Table 2). The other 23 genes accounted for only about $3 \%$ of the total transcripts, of which AAPT1, KAS3, MCAT, FatB, SUC1 and $\alpha-C T$ had the lowest transcript levels (Table 2).

\section{Comparison of the Mean Transcript Levels between ZY82 I and ZS9}

For most of the genes investigated, the transcript levels changed with time during seed development (Fig. 2). Comparison of the mean transcript levels of ZS9 and
ZY821 revealed that 11 of the 32 genes (FAD3, ACCase, FAE1, GKTP, Caleosin, GAPDH, PEPC, KACD, KAS1, LPAAT and MCAT) were upregulated by $20 \%$ to $109 \%$, whereas 10 of the 32 genes (KAS3, $\beta-C T, B c R K 6, P 450$, FatA, Oleosin, FAD6, FatB, $\alpha-C T$ and SUC1) were downregulated by between $20 \%$ and $50 \%$ (Table 2 and Fig. 2).

Among the upregulated genes, FAD3, ACCase and FAE1 were the most remarkable. During 20-30 DAPs, the transcripts of FAD3 were 130 180\% more abundant in ZS9 than in ZY821 (Fig. 2M). In ZY821 the ACCase transcript stayed stable at low levels, whereas in ZS9 it displayed high and low peaks at 25-30 DAPs and 40 DAP, about 4 fold and 2 fold the levels in ZY821, respectively (Fig. 2A). FAE1 gene transcripts were $150 \%-480 \%$ more abundant in ZS9 than in ZY821 during 15-35 DAPs. At 30 DAP, more than 4-fold higher FAE1 transcript levels were 

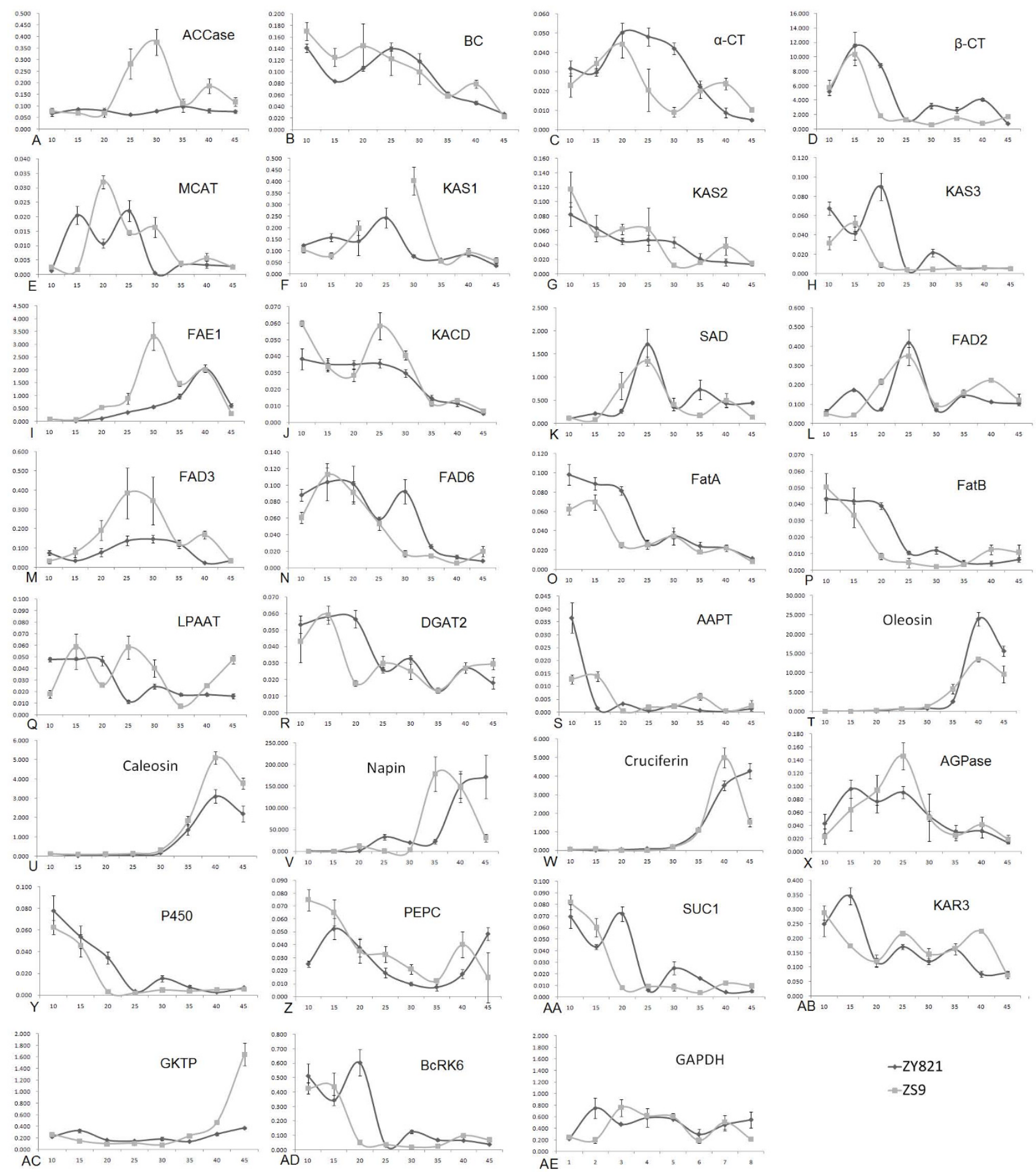

\section{Figure 2}

The expression profile of fatty acid synthesis genes during seed development. (A-D) ACCase gene family. (E-J) Genes involved in fatty acid elongation. (K-N) Desaturase. (O-P) Thioesterase. (Q-S) Genes involved in TAG synthesis. (T-W) Oil body proteins. (X-AE) Other basic metabolism genes. Abbreviated names for the genes are defined in Table 4. Values in parentheses indicate the relative copy number and Values in abscissa indicate the seed development stage. The black curves represent ZY82I and the gray curves represent ZS9. Each data point represents the mean \pm SD of three replicates. 
observed in ZS9 than in ZY821 (Fig. 2I). Caleosin and GKTP transcripts were more abundant only during the final stage of seed development (Fig. 2U, AC).

Among the downregulated genes, KAS3 showed significantly lower expression at 10 and 20 DAPs (Fig. 2H), FatA at 10-20 DAPs (Fig. 2O), BcRK6 and P450 at 20 DAP (Fig. $2 A D, Y$ ), $\beta-C T$ at 20-40 DAPs (Fig. 2D) and Oleosin at 4045 DAPs (Fig. 2T).

\section{Comparison of the ZY82 I and ZS9 Transcript Peak Levels} The value and time of a transcript's peak levels are an indication of gene activity and regulation. ZY821 and ZS9 had different peak values and times for the expression of many of the genes investigated. The peak value was 338\%, 288\% and $162 \%$ higher in ZS9 than in ZY821 for FAD3, ACCase and GKTP, respectively (Table 2 and Fig. $2 \mathrm{M}, \mathrm{A}, \mathrm{AC}$ ), and 40-60\% higher in ZS9 than in ZY821 for KAS2, MCAT, AGPase, PEPC, KACD, FAE1, Caleosin, KAS1 and GAPDH (Table 2 and Fig. 2G, E, X, Z, J, I, U, F, AE). The peak value was over $60 \%$ lower for $A A P T 1$ and $20-40 \%$ lower for Oleosin, KAS3, FatA, BcRK6, SAD and P450 in ZS9 than in ZY821 (Fig. 2S, T, H, O, AD, K, Y).

According to the peak time of gene expression, the 32 genes can be clustered into 4 groups. In ZS9, 12 genes (P450, KCR2, SUC1, FatB, BC, KAS2, PEPC, KACD, AAPT1, FatA, BcRK6, KAS3) peaked at 10 or 15 DAPs, 8 genes $(\alpha-C T, M C A T, G A P D H, S A D, F A D 2, L P A A T$, AGPase, FAD3) at 20-25 DAPs, 4 genes (FAE1, KAS1, ACCase and Napin) at 30-35 DAPs and 4 genes (Oleosin, Cruciferin, Caleosin, and GKTP) at 40-45 DAPs. In ZY821, 15 genes (P450, FatB, BC, KAS2, KACD, AAPT1, FatA, KCR2, PEPC, $\beta$-CT, DGAT2, FAD6, GAPDH, LPAAT and AGPase) peaked at 10 or 15 DAPs, 8 genes (SUC1, KAS3, BcRK6, $\alpha-C T, M C A T, S A D, F A D 2, K A S 1)$ at 20-25 DAPs, 2 genes (ACCase and FAD3) at 20-25 DAPs, and 7 genes (FAE1, Oleosin, Caleosin, $\beta$-actin, Napin, Cruciferin and GKTP) at 40-45 DAPs. In most cases, the difference in peak times between the two cultivars was no more than 5 days, but LPAAT and AGPase peaked 10 days later in ZS9 than in ZY821, whereas SUC1 and Napin peaked 10 days earlier.

\section{Comparison of Gene Expression Patterns between ZY82 I and ZS9}

Different genes showed different degrees of variation in their transcript levels over the course of seed development, as shown by the variation coefficients in Table 2 . In ZY821, AAPT1, Oleosin, Cruciferin, NapinB, Caleosin, FAE1, $P 450$ and KAS3 had relatively higher variation, whereas in ZS9, Cruciferin, NapinB, P450, GKTP, Caleosin, Oleosin, $B c R K G$ and SUC1 did. $\beta$-actin had the lowest variation in both cultivars, serving as a satisfactory control gene in this study.
The 32 genes can be divided into five groups according to their expression patterns.

The first group is characterized by a basic transcript level at the initiation of seed formation, a rapid rise to a peak at 35-40 DAP, and then by a gradual decline. The genes for storage proteins, such as Napin, Caleosin, Cruciferin, and Oleosin, possessed this pattern (Fig. 2T, U, V, W). The expression patterns of these genes were much like the accumulation pattern of the total fatty acids, C18:1 in ZS9 (Fig. 1D) and C22:1 in ZY821 (Fig. 1J).

The second group is characterized by a bell-shape transcript curve, with a moderate level of expression at the initial stage followed by a gradual increase in transcripts at the middle stage and a decline to the initial level at the final stage. The genes SAD, FAD2, FAD3, KAS1, AGPase, $M C A T$ and FAE1 possessed this pattern (Fig. $2 \mathrm{~K}, \mathrm{~L}, \mathrm{M}, \mathrm{F}$, $\mathrm{X}, \mathrm{E}, \mathrm{I})$. These enzymes may function in fatty acid synthesis. The accumulation of the fatty acids C18:1 and C20:1 in ZY821 (Fig. 1D, H) also fell into such a pattern.

The third group is characterized by a low transcript level at the beginning, followed by further decreasing expression throughout seed development, as exhibited by FAD6, FatA, FatB, $\alpha-C T, B C$, PEPC, KCR2, and KACD (Fig. $2 \mathrm{~N}, \mathrm{O}$, P, C, B, Z, J). The fatty acids C16:0, C18:0, C18:2, C20:0, and $\mathrm{C} 22: 0$, which are minor components in mature seeds once synthesized in early seed development, also showed such a pattern (Fig. 1B, C, E, G, I).

The fourth group is characterized by a stable expression or a gently rise and fall in expression pattern. GKTP, ACCase, KAS2, DGAT2 and $\beta$-actin are included in this group (Fig. 2AC, A, G, R). The fatty acid $\alpha-\mathrm{C} 18: 3$ had a similar pattern to this group (Fig. 1F). The fifth group is characterized by a high level of expression at the initiation of seed development, peaking at 10 or $15 \mathrm{DAP}$, followed by an abrupt decline, as exhibited by $\beta-C T, B C R K 6, K A S 3, A A P T 1$, SUC1 and $P 450$ (Fig. 2D, AD, H, S, AA).

A comparison of ZS9 and ZY821 indicated that most of the genes displayed similar expression patterns, although a few of the genes, such as ACCase, FAE1 and GKTP, had obvious differences between ZY821 and ZS9 (Fig. 2A, I, AC). ACCase had a bell-shape expression pattern in ZS9, putting it in the second group, whereas it had a flat pattern in ZY821, putting it in the third group (Fig. 2A). FAE1 was in the first group of expression pattern in ZY821 but had a bell-shape pattern in ZS9, putting it in the second group (Fig. 2I). GKTP also showed a significant difference, with a significant rise in transcript levels at the mature stage of seed development in ZS9, placing it in third group, although it had a very low level throughout all stages of seed development in ZY821 (Fig. 2AC). 
Table 3: The correlation coefficients for the gene expression pattern and the fatty acid accumulation pattern I),2).

\begin{tabular}{|c|c|c|c|c|c|c|c|c|c|c|c|c|c|c|c|c|c|}
\hline Note ${ }^{3)}$ & & $\begin{array}{c}\text { Total- } \\
\text { ZS9 }\end{array}$ & $\begin{array}{c}\text { Cl6:0- } \\
\text { ZS9 }\end{array}$ & $\begin{array}{c}\text { Cl8:0- } \\
\text { ZS9 }\end{array}$ & $\begin{array}{c}\text { Cl8:I- } \\
\text { ZS9 }\end{array}$ & $\begin{array}{c}\text { Cl8:2- } \\
\text { ZS9 }\end{array}$ & $\begin{array}{c}\text { Cl8:3- } \\
\text { ZS9 }\end{array}$ & $\begin{array}{l}\text { Total- } \\
\text { ZY82I }\end{array}$ & $\begin{array}{l}\mathrm{Cl6:0-} \\
\text { ZY82I }\end{array}$ & $\begin{array}{l}\text { Cl8:0- } \\
\text { ZY82I }\end{array}$ & $\begin{array}{l}\mathrm{Cl} 8: \mathrm{I}- \\
\text { ZY82I }\end{array}$ & $\begin{array}{l}\mathrm{Cl} 8: 2- \\
\text { ZY82I }\end{array}$ & $\begin{array}{l}\text { Cl8:3- } \\
\text { ZY821 }\end{array}$ & $\begin{array}{l}\text { C20:0- } \\
\text { ZY82I }\end{array}$ & $\begin{array}{l}\text { C20:I- } \\
\text { ZY82I }\end{array}$ & $\begin{array}{l}\text { C22:0- } \\
\text { ZY821 }\end{array}$ & $\begin{array}{l}\text { C22:I- } \\
\text { ZY82I }\end{array}$ \\
\hline 2 & Oleosin & 0.83 & -0.80 & -0.74 & 0.76 & -0.62 & -0.22 & 0.57 & -0.63 & -0.58 & -0.03 & -0.63 & -0.62 & -0.49 & 0.44 & -0.41 & 0.81 \\
\hline 2 & Cruciferin & 0.81 & -0.65 & -0.58 & 0.61 & -0.49 & -0.23 & 0.48 & -0.62 & -0.58 & -0.10 & -0.63 & -0.45 & -0.56 & 0.42 & -0.38 & $\underline{0.83}$ \\
\hline 2 & Caleosin & $\underline{0.85}$ & -0.77 & -0.70 & 0.73 & -0.60 & -0.33 & 0.48 & -0.68 & -0.62 & -0.17 & -0.72 & -0.30 & -0.50 & 0.54 & -0.37 & $\underline{0.90}$ \\
\hline 2 & $\beta-C T$ & $\overline{-0.61}$ & 0.82 & $\underline{0.84}$ & -0.82 & 0.81 & -0.12 & -0.51 & 0.51 & 0.44 & 0.40 & 0.55 & 0.48 & 0.21 & -0.41 & 0.16 & -0.84 \\
\hline 2 & FAD3 & -0.34 & 0.33 & $\overline{0.22}$ & -0.26 & 0.11 & $\underline{0.88}$ & -0.41 & 0.33 & 0.34 & 0.18 & 0.41 & 0.81 & 0.15 & -0.25 & 0.22 & $\overline{-0.62}$ \\
\hline 2 & $B C$ & -0.68 & $\underline{0.92}$ & $\underline{0.96}$ & -0.94 & $\underline{0.95}$ & -0.10 & -0.56 & 0.62 & 0.60 & 0.16 & 0.69 & 0.54 & 0.40 & -0.53 & 0.39 & -0.87 \\
\hline 2 & PEPC & -0.53 & $\underline{0.85}$ & $\underline{0.90}$ & -0.85 & $\underline{0.86}$ & -0.17 & -0.70 & 0.77 & 0.71 & -0.21 & 0.7 I & -0.48 & 0.60 & -0.80 & 0.54 & -0.59 \\
\hline 2 & FAD6 & -0.60 & $\underline{0.88}$ & $\underline{0.91}$ & -0.87 & $\underline{0.86}$ & -0.10 & -0.58 & 0.74 & 0.69 & -0.13 & 0.69 & 0.22 & 0.55 & -0.58 & 0.55 & -0.77 \\
\hline 2 & ACCase & 0.02 & $\overline{0.03}$ & $-\overline{-0.05}$ & 0.04 & -0.17 & $\underline{0.91}$ & -0.71 & 0.79 & 0.72 & -0.24 & 0.7 I & -0.02 & 0.71 & -0.67 & 0.57 & -0.69 \\
\hline 2 & FatA & -0.51 & 0.81 & $\underline{0.86}$ & -0.80 & 0.80 & $\overline{-0.08}$ & -0.70 & 0.72 & 0.70 & -0.11 & 0.70 & 0.26 & 0.47 & -0.64 & 0.57 & -0.76 \\
\hline 2 & FatB & -0.51 & 0.82 & $\overline{0.89}$ & -0.83 & $\underline{0.87}$ & -0.26 & -0.58 & 0.78 & 0.76 & -0.32 & 0.74 & 0.20 & 0.64 & -0.62 & 0.69 & -0.72 \\
\hline 2 & AAPTI & -0.52 & 0.82 & $\underline{0.89}$ & -0.83 & $\underline{0.86}$ & -0.20 & -0.51 & 0.59 & 0.67 & -0.55 & 0.62 & 0.29 & 0.57 & -0.55 & 0.78 & -0.43 \\
\hline 2 & KCR2 & -0.48 & 0.77 & $\overline{0.82}$ & -0.80 & $\underline{0.86}$ & -0.06 & $\underline{-0.84}$ & $\underline{0.95}$ & $\underline{0.95}$ & -0.39 & $\underline{0.94}$ & $\underline{0.14}$ & $\underline{0.90}$ & -0.86 & 0.82 & $\underline{-0.85}$ \\
\hline 1 & FAEI & 0.49 & -0.57 & -0.61 & 0.58 & -0.61 & 0.58 & 0.75 & -0.88 & -0.84 & 0.21 & -0.87 & 0.18 & -0.63 & $\underline{0.89}$ & -0.67 & $\overline{0.78}$ \\
\hline I & Napin & 0.43 & -0.51 & -0.49 & 0.45 & -0.32 & 0.06 & 0.59 & -0.65 & -0.61 & -0.02 & -0.64 & -0.48 & -0.59 & $\overline{0.45}$ & -0.43 & 0.81 \\
\hline I & $\alpha-C T$ & -0.46 & 0.76 & 0.80 & -0.74 & 0.74 & -0.14 & 0.03 & 0.12 & 0.08 & 0.07 & 0.08 & 0.47 & -0.02 & 0.08 & 0.07 & -0.27 \\
\hline 1 & KASI & -0.29 & 0.35 & 0.35 & -0.34 & 0.26 & 0.11 & -0.59 & 0.55 & 0.48 & 0.51 & 0.63 & 0.18 & 0.27 & -0.56 & 0.10 & -0.89 \\
\hline 1 & KAS2 & -0.50 & 0.75 & 0.73 & -0.72 & 0.69 & 0.31 & -0.43 & 0.40 & 0.30 & 0.18 & 0.30 & 0.02 & 0.13 & -0.31 & 0.11 & $\overline{-0.48}$ \\
\hline 1 & $\beta$-actin & 0.38 & -0.40 & -0.48 & 0.46 & -0.56 & 0.77 & -0.07 & -0.13 & -0.08 & -0.45 & -0.20 & 0.54 & 0.06 & 0.23 & 0.15 & 0.29 \\
\hline I & $B c R K 6$ & -0.46 & 0.79 & $\underline{0.85}$ & -0.79 & 0.80 & -0.19 & -0.28 & 0.35 & 0.32 & 0.03 & 0.32 & 0.36 & 0.12 & -0.22 & 0.25 & -0.46 \\
\hline I & KAS3 & -0.47 & 0.78 & $\overline{0.82}$ & -0.76 & 0.76 & -0.16 & -0.45 & 0.47 & 0.44 & -0.01 & 0.44 & 0.27 & 0.21 & -0.39 & 0.36 & -0.54 \\
\hline I & $K A C D$ & -0.43 & 0.50 & 0.43 & -0.44 & 0.31 & 0.70 & -0.55 & 0.58 & 0.56 & 0.16 & 0.63 & 0.51 & 0.32 & -0.50 & 0.37 & $-0.8 I$ \\
\hline I & SUCI & -0.50 & 0.82 & $\underline{0.89}$ & -0.83 & $\underline{0.86}$ & -0.23 & -0.42 & 0.46 & 0.45 & -0.08 & 0.44 & 0.40 & 0.24 & -0.35 & 0.40 & -0.53 \\
\hline 1 & AGPase & -0.52 & 0.54 & $\overline{0.43}$ & -0.46 & 0.30 & 0.69 & -0.56 & 0.72 & 0.66 & -0.18 & 0.68 & -0.27 & 0.72 & -0.65 & 0.49 & -0.63 \\
\hline 1 & DGAT2 & -0.46 & 0.78 & 0.82 & -0.76 & 0.75 & -0.10 & -0.59 & 0.65 & 0.62 & -0.12 & 0.62 & 0.23 & 0.40 & -0.56 & 0.53 & -0.67 \\
\hline I & GKTP & 0.32 & -0.20 & -0.08 & 0.19 & -0.08 & -0.69 & -0.57 & 0.75 & 0.71 & -0.38 & 0.69 & -0.37 & 0.74 & -0.70 & $0.6 \mathrm{I}$ & -0.53 \\
\hline 1 & LPAAT & -0.38 & 0.66 & 0.67 & -0.61 & 0.55 & 0.04 & -0.57 & 0.75 & 0.72 & -0.28 & 0.70 & 0.25 & 0.60 & -0.58 & 0.65 & $-0.7 \mid$ \\
\hline I & P450 & -0.51 & 0.82 & $\underline{0.88}$ & -0.83 & $\underline{0.86}$ & -0.22 & -0.47 & 0.61 & 0.64 & -0.38 & 0.61 & 0.40 & 0.50 & -0.48 & 0.68 & -0.56 \\
\hline 0 & $S A D$ & -0.36 & 0.14 & $\overline{0.00}$ & -0.10 & $\overline{-0.04}$ & 0.55 & -0.04 & -0.21 & -0.23 & 0.59 & -0.11 & 0.34 & -0.29 & 0.13 & -0.44 & -0.13 \\
\hline 0 & MCAT & -0.47 & 0.13 & 0.03 & -0.13 & 0.04 & 0.07 & -0.47 & 0.54 & 0.48 & 0.09 & 0.55 & -0.29 & 0.52 & -0.55 & 0.24 & -0.57 \\
\hline 0 & FAD2 & -0.17 & -0.06 & -0.19 & 0.08 & -0.13 & 0.57 & -0.44 & 0.51 & 0.47 & 0.07 & 0.54 & -0.19 & 0.51 & -0.51 & 0.24 & -0.55 \\
\hline 0 & GAPDH & -0.46 & 0.14 & 0.03 & -0.14 & 0.04 & 0.20 & -0.35 & 0.48 & 0.43 & -0.14 & 0.45 & -0.39 & 0.54 & -0.46 & 0.29 & -0.36 \\
\hline
\end{tabular}

Note: I) Significant levels: $\mathrm{r} 0.05=0.707, \mathrm{r} 0.0 \mathrm{I}=0.834$

2) Bold numbers indicate the correlation is significant ( 0.05 probability level); Underlined bold numbers indicate the correlation is highly significant ( 0.01 probability level).

3) Zero means the gene shows no significant correlation with any fatty acid in either cultivar. One means the gene shows no significant correlation with any fatty acid in one cultivar; two means the gene shows significant correlations in both cultivars. 


\section{Correlation between fatty acid accumulation and gene expression}

Correlation analysis was performed between transcript profiles of the genes and accumulation patterns of the fatty acids. The results showed that the two cultivars had different correlation patterns (Table 3). For the Low Erucic Acid Rapeseed (LEAR) ZS9, the total amount of fatty acids was highly correlated with Caleosin and correlated with Cruciferin and Oleosin; the amount of C16:0 was highly correlated with BC, PEPC and FAD6 and correlated with Oleosin, $\alpha-C T, K A S 2, \beta-C T, B c R K 6, S U C 1$, DGAT2, FatA, P450, FatB, AAPT1, and KCR2; C18:0 was highly correlated with SUC1, $\beta-C T, B C$, PEPC, FAD6, FatA, P450, FatB, and AAPT1, positively correlated with KCR2, DGAT2, KAS3, BcRK6, KAS2, and $\alpha-C T$, and negatively correlated with Oleosin; C18:1 was highly negatively correlated with $B C$, FAD6 and PEPC, negatively correlated with AAPT1, FatB, SUC1, P450, $\beta-C T, F a t A, K C R 2$, BcRK6, KAS3, $D G A T 2, \alpha-C T$, and KAS2 and positively correlated with Caleosin and Oleosin; C18:2 was highly positively correlated with BC, FatB, AAPT1, FAD6, SUC1, PEPC, P450 and KCR2 and correlated with $\beta-C T, F a t A, B c R K 6, K A S 3$, DGAT2 and $\alpha-C T$; C18:3 was highly positively correlated with ACCase and correlated with FAD3. For High Erucic Acid Rapeseed (HEAR) ZY821, the total amount of fatty acids was highly negatively correlated with KCR2, negatively correlated with ACCase and positively correlated with FAE1. C16:0 was highly positively correlated with KCR2, positively correlated with AGPase, PEPC, FAD6, ACCase, FatA, GKTP, LPAAT, and FatB and negatively correlated with FAE1; no significant correlation for C18:1 was found with any gene; C18:2 was highly positively correlated with KCR2 and highly negatively correlated with FAE1, positively correlated with FatB, ACCase, and PEPC and negatively correlated with Caleosin; C18:3 was correlated only with FAD3; C20:0 was highly positively correlated with KCR2 and correlated with AGPase, ACCase, and GKTP; C20:1 was highly positively correlated with FAE1, highly negatively correlated with KCR2 and negatively correlated with PEPC; C22:1 was highly positively correlated with Caleosin and Cruciferin, highly negatively correlated with KAS1, BC, KCR2 and $\beta-C T$, positively correlated with Napin, Oleosin, and FAE1, and negatively correlated with KACD, FAD6, FatA, FatB, and LPAAT.

The genes Napin, KACD, AGPase, GKTP, and LPAAT in LEAR ZS9 and the genes $\alpha-C T, K A S 2, B c R K 6, K A S 3, S U C 1$, DGAT2, and P450 in HEAR ZY821 showed no significant correlation with any fatty acids or with the total amount of fatty acids.

\section{Discussion}

Many efforts by plant breeders have focused on strategies to enhance both the quantity and the quality of seed storage reserves and, more recently, molecular genetics approaches have been used to modify seed components. The biochemical pathways that produce these different storage components are largely known [7-9], but the factors that determine the relative proportions of the different storage components are not well understood. This study has provided a new data set describing the patterns of expression of 32 rapeseed genes during storage product accumulation in seed development and characterizing the response of gene expression to quality improvement in rapeseed.

The present study indicated that the expression levels of specific genes changed with the selection pressures when ZS9 and ZY821 were compared. Seven of the 32 genes (FAD3, ACCase, FAE1, GKTP, Caleosin, GAPDH, and PEPC) were upregulated by $30 \%$ to $109 \%$, whereas 5 genes (KAS3, $\beta-C T, B c R K 6, P 450$ and FatA) were downregulated $50 \%-30 \%$ in ZS9 compared with ZY821. These changes may come from selection pressures or from genetic drift during breeding.

\section{Genes studied}

Lipid synthesis depends on the correct spatial and temporal activity of many gene products $[7,8]$. These genes execute their function in three stages: fatty acid synthesis in the plastid, triacylglycerol (TAG) synthesis in the endoplasmic reticulum (ER) and assembly into an oil body [10].

The first fatty acid synthesis stage commences with ACCase, catalyzing the carboxylation of acetyl-CoA to malonyl-CoA [11]. Most plants have two forms of ACCase, the homomeric form in the cytosol, composed of a single large polypeptide catalyzing the individual carboxylation reactions [12], and the heteromeric form in plastids, composed of four subunits, including Biotin Carboxylase $(B C)[13]$, Biotin Carboxyl Carrier Protein $(B C C P)[14], \alpha$-Carboxyltransferase $(\alpha-C T)[15]$ and $\beta$ Carboxyltransferase $(\beta-C T)[16]$.

The next enzyme is MCAT (Malonyl-CoA-acyl carrier protein transacylase), which catalyzes the transfer of malonylCoA to the holo acyl carrier protein (ACP), generating malonyl-ACP [17]. Beta-ketoacyl-acyl carrier protein synthase III (KAS3) catalyzes the subsequent condensation and transacylation of acetyl-CoA with malonyl-ACP [18]. KAS1 catalyzes the subsequent condensation from C4- to C14-ACP in the plastid [19], and KAS2 elongates 16:0ACP to 18:0-ACP in the plastid [20].

The synthesized 18:0-ACP is converted to oleic acid (18:1) by $S A D$ [21]. In HEAR cultivars such as ZY821, the oleic acids (18:1) continue the elongation process to synthesize C20- to C22- fatty acids such as erucic acid (22:1), which involves four enzymatic steps: condensation by 3-ketoa- 
cyl-CoA synthase (FAE1) [22], reduction by 3-ketoacylCoA reductase (KCR) [23], dehydration by 3-hydroxyacylCoA dehydratase (KACD) [24] and finally reduction by trans-2,3-enoyl-CoA reductase. In LEAR cultivars, such as ZS9, fatty acids do not elongate any more due to the disfunction of FAE1 $[25,26]$.

Oleic acid (18:1) can be further desaturated to oleate acids (18:2) by FAD2 [27] and FAD6 [28] in the cytosol and the plastid, respectively. Cytosolic and plastid $\omega-3$ desaturations that result in the production of linolenic acids (18:3) are controlled by FAD3 [29] and FAD7 [30], respectively.

The final step in the plastid is the release of fatty acids from ACP by thioesterase, resulting in the formation of dissociated fatty acids [31]. Two distinct but related thioesterase gene classes exist in higher plants. FatA is an acyl specificity 18:1 >18:0 > 16:0 thioesterase [32]. In contrast, FatB, encoding thioesterases, has a specificity for 16:0>18:1>18:0 fatty acids [33]. Fatty acids are exported to the cytosol and activated to their acyl-CoA derivatives.

In the following stage, fatty acids are incorporated into glycerolipids through the acylation of glycerol-3-phosphate by acyltransferases, producing TAG. De novo phosphatidic acid biosynthesis in plants occurs in three steps: first, the acylation of the sn-1 position of glycerol-3-phosphate gives rise to lysophosphatidic acid, which is catalyzed by Glycerol-Phosphate Acyltransferase (GPAT) [34]; second, the acylation of the sn-2 position forms phosphatidic acid, which is catalyzed by a lysophosphatidic acid acyltransferase (LPAAT) [35]. Diacylglycerol acyltransferase (DGAT) catalyzes the final step of the TAG synthesis pathway [36].

The TAG assembles with oil body proteins to form oil bodies. There are four predominant seed storage proteins: Cruciferin, Caleosin, Oleosin and Napin. Cruciferin is a high molecular weight neutral complex of $12 \mathrm{~S}$ proteins, composed of six subunit pairs [37]. Napin is a low molecular weight basic $1.7 \mathrm{~S}$ protein, composed of two disulfidelinked polypeptide chains [38]. Caleosin is a $\mathrm{Ca}^{2+}$-binding oil-body surface protein [39] playing a role in both the normal modification of storage vacuole membranes and the interaction of oil bodies with vacuoles [40]. Oleosins are oil body-associated proteins that cover and stabilize oil bodies during TAG accumulation [41].

\section{Relative transcript levels of genes in the developing seed}

According to DeLisle and Crouch [42], mRNA is about 1\% of the total RNA in B. napus embryos. Cruciferin and Napin represent 11 and 8\%, respectively, of embryonic mRNA based on mass [42]. Cruciferin and Napin constitute 20\% and $60 \%$ of the total protein content of mature seeds, respectively [43]. Moreover, Napin (12.5-14.5 kDa) is about 25 fold smaller in mass (2S albumin) than Cruciferin (12S globulin, 300-310 kDa) [43]. All of this implies that Napin mRNA is the most abundant and is much higher in copy number than Cruciferin mRNA during rapeseed development, in agreement with our results. With the strongest expression in seed, the Napin promoter has been popularly used for genetic engineering of seed components.

No estimate of the relative mRNA abundance has been reported for Oleosin and Caleosin in B. napus thus far, but it has been reported that Oleosins are low molecular weight (15-26 kDa) alkaline proteins that represent about $2-8 \%$ of the total seed proteins [44], and Caleosins are present at relatively low levels and are mainly bound to microsomal membrane fractions [45]. Our data are the first on the relative abundance of Oleosin and Caleosin transcripts in rapeseed development, indicating that Oleosin transcripts are the second most abundant in copy number after Napin among the 4 storage proteins (Table 2).

No significant difference was found in the relative abundance of seed mRNA between ZY821 and ZS9, indicating that the genes are expressed in a highly organized and coordinated way and in a stable molar amount during seed development.

\section{Upregulated genes (FAD3, ACCase, FAEI, GKTP, Caleosin, GAPDH, PEPC)}

PEPC, upregulated by $39 \%$ in ZS9 compared with ZY821, is an enzyme in the family of carboxylyases that catalyzes the addition of $\mathrm{CO}_{2}$ to phosphoenolpyruvate (PEP) to form the four-carbon compound oxaloacetate. Seeds of transgenic bean plants expressing Corynebacterium glutamicum PEPC in a seed-specific manner had a more rapid shift in metabolic fluxes from sugars/starch into organic acids and free amino acids [46], resulting in an accumulation of up to $20 \%$ more protein per gram dry seed weight in the transgenic seeds and a $20-30 \%$ higher seed dry weight [46]. We show that PEPC upregulation may result in increased C16:0, C18:0 and C18: 2 but decreased C18:1 (Table 3).

ACCase, upregulated by $105 \%$ in ZS9 compared with ZY821, is the homomeric ACCase that catalyzes the first committed step of fatty acid synthesis, the carboxylation of acetyl-CoA to malonyl-CoA. Targeting a homomeric ACCase to rapeseed plastids under the control of a seedspecific promoter resulted in higher ACCase activity and increased oil yield by $3-5 \%$ on a dry seed weight basis [12]. Over-expression of ACCase in the amyloplasts of potato tubers led to an increase in fatty acid synthesis and a more than 5-fold increase in the amount of TAG [47]. ACCase is a key target to increase seed oil by genetic engi- 
neering [12,47]. In the present study, increased ACCase activity was accompanied with increased C18:3 in ZS9 and with increased C16:0, C18:0, C20:2 and C18:2 and decreased total fatty acids in ZY821. Considering that C18:3 does not change much with seed development, increased C18:3 must be consumed at a similar amount during seed development.

FAE1, upregulated by $80 \%$ in ZS9 compared with ZY821, is a key gene responsible for fatty acid elongation from 18:1 to 22:1 or erucic acid biosynthesis in Brassica. Seedspecific expression in Arabidopsis thaliana resulted in up to a 12 -fold increase in the proportion of erucic acid. On the other hand, in transgenic high-erucic Brassica carinata plants, the proportion of erucic acid was as high as 51.9\% in the best transgenic line, a net increase of $40 \%$ compared with wild type [48]. FAE1 mRNA was normally transcribed in both HEAR and LEAR cultivars but a $57 \mathrm{kDa}$ protein was found only in HEAR seeds, whereas it was absent in all LEAR cultivars using an antibody against FAE1 $[26,49]$. It was beyond our expectation that the FAE1 transcript was more abundant in LEAR ZS9 than in HEAR ZY821 (Fig. 2I). The upregulated FAE1 transcript observed in this study (Fig. 2I) might be due to synthesized FAE1 mRNA that was not used for the blocked synthesis of functional FAE1 enzyme.

FAD3 was upregulated by $109 \%$ in ZS9 compared with ZY821 (Table 2) and was significantly correlated only with C18:3 in the present study (Table 3). No significant difference in C18:3 content is found during seed development between ZY821 and ZS9 (Fig. 1D). Why the FAD3 transcript level was up-regulated by so much and no more C18:3 was found in ZS9 needs further investigation. It is worthwhile to notice that the FAD 3 and FAE1 changed coodinately (Fig. 2I, M), consistent with previous reports that they are both regulated by abscisic acid (ABA) [5]. Some key transcription factors involved in lipid metabolism are under the influence of ABA signaling [5]. The upregulation of $F A D 3$ found in this study may be linked through some regulation cofactors with the upregulation of FAE1 in ZS9.

Abscisic acid induces Oleosin expression [50], and FAD3 and FAE1 also are regulated by abscisic acid [51-53]. The upregulation of FAD3, FAE1 and Oleosin found in this study might be owing to the same regulation cofactor. The breeding pressure may have selected for the action of this cofactor.

Caleosin, one of the storage proteins, was upregulated by $60 \%$ in ZS9 compared with ZY821 (Table 2). It was significantly correlated with total fatty acids and C18:1 in ZS9 and with C22:1 in ZY821 (Table 3). Meanwhile, transcrips of other storage proteins (Cruciferin, Oleosin and Napin) were all downregulated. Unlike Oleosin, Caleosin may be involved in signal transduction via calcium binding or phosphorylation/dephosphorylation in processes such as membrane trafficking and lipid-body fusion [39]. During germination Caleosin plays a role in the degradation of storage lipid in oil bodies [40]. Upregulation of Caleosin implies enhanced oil deposition and improved seed germination in ZS9.

GKTP (synonym KAT2), upregulated by $66 \%$ in ZS9 compared with ZY821, codes for the precursor of glyoxysomal 3-ketoacyl-CoA thiolase, the last enzyme in the beta-oxidation of fatty acids in plant glyoxysomes. Expression of this enzyme is required for the timely onset of natural and dark-induced leaf senescence in Arabidopsis [54]. In this study, the transcript abundance of GKTP is correlated with C16:0, C18:0 and C20:0 in ZY821 but not with any fatty acid in ZS9. The reason for this difference is not clear.

GAPDH, upregulated by 56\% in ZS9 compared with ZY821, encodes glyceraldehyde 3-phosphate dehydrogenase, which catalyzes the sixth step of glycolysis and thus serves to break down glucose for energy and carbon molecules. In addition to this long established metabolic function, GAPDH has recently been implicated in several non-metabolic processes, including transcription activation, initiation of apoptosis, and ER to Golgi vesicle shuttling. In this study, GAPDH showed relatively stable and high expression among the non-storage protein genes during seed development. The activity of GAPDH was not found to be correlated with any fatty acid biosynthesis in this study (Table 3).

\section{Down-regulated genes (KAS3, $\beta-C T$, BcRK6, P450 and FatA)}

KAS3 was down regulated by $51 \%$ in ZS9 compared with ZY821 (Table 2). It was also found to be significantly correlated with C16:0, C18:0 and C18:2 in ZS9 but not in ZY821. Katayoon et al. indicated that overexpression of KAS3 in tobacco plants reduces the rate of lipid synthesis and increases the levels of C16:0 in leaves. The transgenic $B$. napus seeds overexpressing KAS3 driven by Napin also contained lower levels of oil compared with wild-type [55]. In addition, the rate of lipid synthesis in transgenic rapeseed seeds was notably slower than that of the wildtype seeds [55]. Therefore, down-regulation of KAS3 might result in reduced saturated fatty acids and increased C18:2 in ZS9 (Fig. 1B, C, G). The same situation is also found for P450, FatA, FatB, AAPT1, KCR2, $\alpha-C T, \beta-C T, B C$, SUC1, BcRK6 and KAS2 in this study (Table 3).

FatA was downregulated $32 \%$ in ZS9 compared with ZY821 (Table 2). It was shown in this study that transcript levels of FatA were negatively correlated with C18:1 in ZS9 and with C22:1 in ZY821 (Table 3). In both cultivars, the 
transcripts of FatA peaked at 10 or 15 DAPs, and positively correlated with C16:0 and C18:0 (Table 3). Thioesterases FatA and FatB play an essential role in the partitioning of de novo-synthesized fatty acids between the prokaryotic and eukaryotic pathways. FatA determines the in vivo levels of C18:1 that move out from the plastid [31]. Downregulated FatA means lower levels of C18:1 move out from the plastid. This is reasonable because C18:1 was not consumed for C22:1 in ZS9, high accumulation of C18:1 must inhibit transcription of FatA. Similar situations were found for FatB (Table 3).

As one of the 4 subunits of the multisubunit plastidial ACCase, $\beta$-CT was downregulated $36 \%$ in ZS9 compared with ZY821. The transcript abundance of $\beta-C T$ was much higher than other subunits of the multisubunit plastidial ACCase and ranked the third just next to Napin and Oleosin in both cultivars (Table 2). This is probabally because $\beta$-CT gene is the only component of plant lipid metabolism known to be encoded by the plastid genome [11]. We found downregulation of $\beta$-CT was accompanied by increased C18:1 in ZS9 and higher C22:1 in ZY821 (Table 3 ), while reduction of the expression of $\beta-C T$ was reported to result in reduced fatty acid synthesis and even damage of embryo development [56].

BcRK6, downregulated $36 \%$ in ZS9 compared with $\mathrm{ZY} 821$, is a receptor kinase, catalyzing the key step in steroid perception and signaling in plants [57]. This enzyme was active at 10-20 DAP and was reduced sharply afterward. Decreased BcRKG transcripts were significantly accompanied by increased C18:1 accumulation in ZS9 (Table 3). The reason for the downregulation of BcRK6 in ZS9 observed at 20 DAP needs further investigation.

Cytochrome P450 catalyzes a monooxygenase reaction, e.g., insertion of one atom of oxygen into an organic substrate $(\mathrm{RH})$, whereas the other oxygen atom is reduced to water using a plethora of both exogenous and endogenous compounds as substrates for enzymatic reactions, producing a wide cultivar of susceptibility to specific toxins. Cytochrome P450 enzymes are present in most other tissues of the body and play important roles in hormone synthesis and breakdown (including estrogen and testosterone synthesis and metabolism), cholesterol synthesis, and vitamin $\mathrm{D}$ metabolism. This gene showed significant correlations in ZS9 but correlations were not found in ZY821. The reasons for this difference are not clear.

\section{Correlation analysis}

Most of the genes investigated in this study showed significant correlation with fatty acid accumulation (Table 3 ). We found that the correlation of the genes in ZS9 was significantly different from that in ZY821. For example, significant correlation was not found with any fatty acid in
ZS9 but it was found with 6 fatty acids in ZY821; ACCase is highly significantly correlated with C18:3 in the LEAR ZS9 but not in ZY821, whereas in ZY821, ACCase showed significant correlation with many other fatty acids, including total fatty acids C16:0, C18:0, C20:0, and C18:2. Exceptionally, in both cultivars FAD3 showed significant correlation only with $\mathrm{C} 18: 3$, in accordance with its defined function for the production of $\mathrm{C} 18: 3$ from C18:2 [27].

In ZS9, more tighter correlations were found between gene transcript levels and fatty acid accumulation patterns. In ZS9, thirteen genes including P450, FatB, AAPT1, KCR2, DGAT2, PEPC, FAD6, FatA, BC, SUC1, Oleosin, $\alpha-$ $C T$, and $\beta-C T$, whereas only four genes in ZY821, i.e., KCR2, FAE1, ACCase and FatB, showed significant correlation with at least four fatty acids, indicating that they play important parts in the storage accumulation of seed development. However, in both cultivars, the genes $S A D$, $M C A T$ and FAD2, which among the down regulated genes showed no significant correlation with either any fatty acids or the total amount of fatty acids, did not respond to the breeding progress for fatty acid composition in rapeseed.

According to the frequency of significant correlations, KCR2 seemed of the highest importance in the fatty acid accumulation process. Higher KCR2 activity is associated with higher C16:0, C18:0, and C18:2 in both cultivars, lower C22:1 and total fatty acids in ZY821, and lower C18:1 in ZS9. Bn-KCR was preferentially expressed in seeds and roots. The co-expression of Bn-FAE1 and $B n$ KCR observed in the HEAR cultivar during seed development was different from that of the LEAR cultivar, suggesting that the expression of both genes was directly or indirectly linked [23]. To our knowledge, this is the first time a close correlation between KCR 2 and fatty acid accumulation has been shown.

\section{Conclusion}

This paper illustrated the breeding response of the transcription levels of 32 genes in developing rapeseed seeds of two cultivars. Both cultivars showed similar transcription profiles, with the Napin gene transcribed most predominantly. Selective pressure toward zero erucic acid, low glucosinolate, high oleic acid and high oil content as well as high yield resulted in both higher FAE1, FAD3, Caleosin, LPAAT, KACD, and ACCase and lower FatB, FAD2, SUC1, BCRK6, KAS3, and MCAT expression and in altered correlations between these genes during the storage accumulation of seed development. These results provide insight into the structure of the primary transcriptional networks that coordinate the metabolic responses to seed developmental programs in rapeseed. 


\section{Methods \\ Plant Material}

Both ZY821 and ZS9 are conventional rapeseed cultivars (B. napus), bred by our Institute. ZS9 was the offspring of ZY821 by crossing. Because they are two Chinese representative rapeseed cultivars bred during the past 20 years, they show some major differences, as described in Table 1.

During the flowering stage, flower buds were self-pollinated and bagged after removal of flowered and young buds in the main inflorescence. Developing pods were harvested at 5-day intervals, 10 to 45 DAP. Dissected seeds were frozen immediately in liquid nitrogen and stored at $-70^{\circ} \mathrm{C}$ until gas chromatographic (GC) analysis or RNA extraction.

\section{Selection of Genes}

Thirty-two genes involved in the biosynthesis of storage products in rapeseed (Table 4 ) were identified by exhaustive database searches and by referring to the comprehensive lipid gene catalog provided by Mekhedov et al. [7]. The selected genes cover all of the major biochemical events in the biosynthesis of storage products in rapeseed $[7,58]$. Seed oil is synthesized in three stages: de novo fatty acid synthesis from $\mathrm{C} 2$ to $\mathrm{C} 16$ in the plastid, fatty acid elongation from $\mathrm{C} 16$ to $\mathrm{C} 22$, fatty acid desaturation and TAG synthesis in the ER and assembly into the oil body [10]. The following were identified: four eukaryotic ACCase and prokaryotic plastidial ACCase subunit genes, which catalyze the first reaction in the fatty acid biosynthetic pathway, seven fatty acid elongase genes, which catalyze fatty acid elongation from varied lengths of carbon chains, four fatty acid desaturase genes, which catalyze the subsequent desaturation of the lipids to highly unsaturated forms, two thioesterase genes, which release free fatty acid from an acyl-ACP, three glycerolipid synthesis genes, which catalyze the acylation reactions of free fatty acids with glycerol-3 phosphate, four storage protein biosynthesis genes, six basic metabolism genes, and two housekeeping genes (Table 4). The functions and roles of these genes have been explained in detail by Mekhedov et al. and Ohlrogge and Browse $[7,58]$.

\section{Determination of Gene Transcript Levels}

The transcript levels of genes were analyzed by quantitative reverse transcription (qRT-PCR). Total RNA was extracted according to the protocol described for Arabidopsis seed [59]. RNA pellets were dissolved in DEPC-treated water, quantified by absorbance at $260 \mathrm{~nm}$ and checked for quality by agarose gel electrophoresis. Total RNA samples were reverse transcripted to first-strand cDNA using an Oligo(dT)20 primer and ReverTra Ace- $\alpha$-TM (TOYOBO Inc., Tokyo, Japan). The cDNA products were stored at $-70^{\circ} \mathrm{C}$.
Primers were designed with the Primer Premier 5.0 software (Premier Biosoft International Palo Alto, CA) in order to produce PCR products that were 100-160 bps in size and located near the 3' UTR (Table 4). Optimized primer sets that produced no dimers and showed nearly $100 \%$ amplification efficiency were chosen. Information on optimized primer pairs is given in Table 4 . The optimized conditions allowed for simultaneous analysis of multiple genes in a 96-well plate.

Real-time PCR reactions were performed in triplicate using the SYBR Green PCR Master Mix (TOYOBO Inc., Tokyo, Japan). A standard reaction mixture $(20 \mu \mathrm{L})$ contained $1 \mu \mathrm{L}$ cDNA template, $2 \times$ SYBR Green I Master Mix (TOYOBO Inc., Tokyo, Japan) and $400 \mathrm{nM}$ forward and reverse primers.

The Opticon Monitor 2.0 (MJ Research) was used for all amplifications. The PCR protocol consisted of an initial denaturalization step at $94^{\circ} \mathrm{C}$ for $2 \mathrm{~min}$, followed by 50 repeats of $94^{\circ} \mathrm{C}$ for $10 \mathrm{sec}, 57^{\circ} \mathrm{C}$ for $20 \mathrm{sec}$ and $72^{\circ} \mathrm{C}$ for $30 \mathrm{sec}$. PCR product specificity was confirmed by meltingcurve analysis and by electrophoresis on 2\% ethidium bromide-containing agarose gels to ensure that PCR reactions were free from primer dimers and non-specific amplicons.

For each gene, triplicate sets of PCR reaction samples were prepared and run in a 96-well plate. The PCR experiments were repeated for each plate to ensure that similar results were obtained. SYBR Green fluorescence was analyzed by Opticon Monitor 2.0 (MJ Research) software and the CT value for each sample was recorded for further analysis.

\section{Determination of PCR Efficiency for the 32 Genes}

PCR efficiency was assayed for each gene. Plasmid DNA containing the gene of study was diluted in 5 serial tenfold dilutions. An XY (scatter) plot was drawn and the linear regression equation was developed with the log input for the X values and the CT (Cycle of threshold) for the Y values. The results are listed in Table 4 . The regression slope was used to calculate the PCR efficiency according to the following equation.

$$
\text { PCR efficiency }=10^{-(1 / \text { slope })}-1
$$

\section{Quantitative RT-PCR Data Analysis}

The relative expression ratio of each gene compared with the control gene $\beta$-actin was determined using the Pfaffl method [60] and defined as Transcript Level (TL) in this paper. The relative expression ratio is calculated only from the real-time PCR efficiencies and the crossing point deviation of an unknown sample versus a control [60]. This model needs no calibration curve. Control levels were 
Table 4: Primer pairs and amplicon sizes of the genes analyzed in this study.

\begin{tabular}{|c|c|c|c|c|c|c|}
\hline Categry & $\begin{array}{l}\text { Accession } \\
\text { number }\end{array}$ & $\begin{array}{l}\text { Gene } \\
\text { name }\end{array}$ & Gene annotation & Primer sequence & Amplicon size(bp) & PCR efficency \\
\hline \multirow[t]{8}{*}{ ACCase } & X77382 & ACCase & Homomeric acetyl CoA carboxylase & F:5'AGGACTTGCCAATCTTCTAAAC3' & 157 & 0.973 \\
\hline & & & & R:5'AGCTTCTTTCACCGTAGGACAC3' & & \\
\hline & AY538675 & $\alpha-C T$ & alpha-carboxyltransferase & F:5'CTTGTCCACCCTATTCTGATTG3' & 106 & 0.958 \\
\hline & & & & R:5'ATGTCCAGCTTAGATTTGAGGC3' & & \\
\hline & Z50868 & $\beta-C T$ & Beta-carboxyltransferase & F:5'CAGCAAGTTTGGGTATGTTGGG 3' & 116 & 1.030 \\
\hline & & & & R:5'GTGAACCTTCAGGCACGGCTTT3' & & \\
\hline & AY0344I0 & $B C$ & Biotin carboxylase & F:5'AGGACCCATTCAAAGGATTCAG3' & 118 & 1.000 \\
\hline & & & & R:5'GCTTGGAGGAACAACATAGTCG3' & & \\
\hline \multirow[t]{8}{*}{ Desaturase } & AY642537 & $S A D$ & Stearoyl-ACP desaturase & F:5'GTTTACACTGCCAAAGACTATGCG3' & 135 & 0.937 \\
\hline & & & & R:5'CCTGATTCTCGGAGTCAACCCAC3' & & \\
\hline & AY592975 & FAD2 & Oleate desaturase & F:5'AGGCGATAAAGCCGATACTTGG3' & 107 & 1.095 \\
\hline & & & & R:5'CCTATCCGGTTCAACATAGATACACT3' & & \\
\hline & AY599884 & FAD3 & Linoleate desaturase & F:5'TTCCCACAAATCCСТСАСТАТСАЗ' & 132 & 0.936 \\
\hline & & & & R:5'ACTTGCCACCAAACTTTCCACC3' & & \\
\hline & AY642535 & FAD6 & Oleate desaturase & F:5'ATCACATAAGCCCAAGGATACCG3' & 116 & 0.953 \\
\hline & & & & R:5'TCGTCTTCATCAACCGCCAATT3' & & \\
\hline \multirow[t]{14}{*}{ Elongase } & AJ007046 & MCAT & $\begin{array}{l}\text { Malonyl CoA-acyl carrier protein } \\
\text { transacylase }\end{array}$ & F:5'ATCATAGGGTTGGACTCAGAAA 3' & 116 & 0.955 \\
\hline & & & & R:5'ACTGCGTAGTTACCCGGACATA 3' & & \\
\hline & AF2445I9 & KASI & Beta-ketoacyl-ACP synthase I & F:5'ACACGGTCGCAAACGAGAAGAA3' & 204 & 0.976 \\
\hline & & & & R:5'GAAGATAATGGTGATGGAGCAG3' & & \\
\hline & AF244520 & KAS2 & Beta-ketoacyl-ACP synthase 2 & F:5'GGAGTACCAAGCCCTTGCTCAC3' & 133 & 0.812 \\
\hline & & & & R:5'TCCTTATGGCCTGCACAGTTGC3' & & \\
\hline & AFI79854 & KAS3 & Beta-ketoacyl-ACP synthase 3 & F:5'GGATGATGGGTTATTTAGTTTC3' & 108 & 0.918 \\
\hline & & & & R:5'CCAAAGGGTAAAGCAGGAGAAG3' & & \\
\hline & AF009563 & FAEI & Fatty acid elongase I & F:5'GTCAGGCTTTAAGTGTAACAGTGCA3' & 159 & 0.957 \\
\hline & & & & R:5'TTATTAGGACCGACCGTTTTGG3' & & \\
\hline & AF382I46 & KACD & 3-keto-acyl-acp dehydratase & F:5'GATAGCGAAAATGGAAGGGAAAG3' & 115 & 0.958 \\
\hline & & & & R:5'AAAGCAAAAGGCACGAGAACATA3' & & \\
\hline & AYI96197 & KCR2 & 3-ketoacyl-CoA reductase & F:5'TGAGTACAAGAAAAGTGGGATTG3' & 101 & 0.983 \\
\hline & & & & R:5'GAGATGCCACTAAGAAAGATGCT3' & & \\
\hline \multirow[t]{4}{*}{ Thioesterase } & BRUI7098 & FatA & Acyl-ACP thioesterase & F:5'GGGACCAATGGCTCTGCATCAT3' & 121 & 0.965 \\
\hline & & & & R:5'GGCTTCTTTCTCCACAGGGTTG3' & & \\
\hline & DQ847275 & FatB & Palmitoyl-ACP thioesterase & F:5'AGTTTGTGGGTGATGATGAATA3' & 107 & 0.944 \\
\hline & & & & R:5'GCAAGGATAGGGTCAGAGTTCA3' & & \\
\hline \multirow[t]{5}{*}{ TAG synthesis } & AFI55224 & DGAT2 & $\begin{array}{l}\text { Acyl-CoA: diacylglycerol } \\
\text { acyltransferase }\end{array}$ & F:5'CATGACCTGATGAACCGCAAAG3' & III & 0.985 \\
\hline & & & & R:5'ACGGCTACCAAAAGGATACAAAA3' & & \\
\hline & AFIIIII6I & LPAAT & $\begin{array}{l}\text { Plastidial lysophosphatidic acid } \\
\text { acyltransferase }\end{array}$ & F:5' CGAAGAGGCGAGAAACAAGATAG3' & 100 & 0.970 \\
\hline & & & & R:5'TGGTTTAGCCTTCTCATTGTTCA3' & & \\
\hline & AYI79560 & AAPTI & Aminoalcoholphosphotransferase & F:5'TGGTGCTTCTTGGTTATTGTAT3' & 156 & 0.821 \\
\hline
\end{tabular}


Table 4: Primer pairs and amplicon sizes of the genes analyzed in this study. (Continued)

\begin{tabular}{|c|c|c|c|c|c|c|}
\hline \multirow{8}{*}{ Oil body protein } & AY570250 & Napin & I.7S oil body protein & R:5'CTTTGGATGCTCCTTTCAAGGT3' & 148 & 0.958 \\
\hline & & & & F:5'GTAATCAATTTGGCCCTTAGCT3' & & \\
\hline & AY966447 & Caleosin & $\begin{array}{l}\text { Ca2+-binding oil body surface } \\
\text { protein }\end{array}$ & R:5'CTCAAGATTCACAGGCATAAAC3' & 116 & 0.952 \\
\hline & & & & F:5'CTGGGAGGCAAAGTTCAGGATA3' & & \\
\hline & $\times 58000$ & Oleosin & oil body associated protein & R:5'CATGGCGTAATTTAGGTAGTGT3' & 122 & 0.969 \\
\hline & & & & F:5'GAGGAGTCAGAGACCGCAGGA3' & & \\
\hline & MI6860 & Cruciferin & I2S neutral oil bodyprotein & R:5'AAGGAAGCGAAGGATGGGGAGA3' & 165 & 0.969 \\
\hline & & & & R:5'GGATTTGCATTATCCTCCCTTG3' & & \\
\hline \multirow[t]{4}{*}{ Housekeep genes } & AFIII8I2 & $\beta$-actin & Housekeeping gene & F:5'CTGGAATTGCTGACCGTATGAG 3' & 145 & 1.001 \\
\hline & & & & R:5'ATCTGTTGGAAAGTGCTGAGGG 3' & & \\
\hline & DQ097338 & GAPDH & $\begin{array}{l}\text { Glyceraldehyde-3-phosphate } \\
\text { dehydrogenase }\end{array}$ & F:5'GCTATCAAGGAGGAATCTGAGGAC3' & 146 & 0.936 \\
\hline & & & & R:5'CTTCACGAAATTGTCACTCAACG3' & & \\
\hline \multirow[t]{12}{*}{ Others } & DQ167I82 & P450 & Cytochrome P450 & F:5'ATGGATCTCGGGATCGGACAGT3' & 156 & 0.954 \\
\hline & & & & R:5'GTCAAGCGATGACGGAGCAAAA3' & & \\
\hline & X930I5 & GKTP & $\begin{array}{l}\text { Glyoxysomal beta-ketoacyl-thiolase } \\
\text { precursor }\end{array}$ & F:5'GTTGGTCCAGCAGTTGCCATTC3' & 159 & 0.934 \\
\hline & & & & R:5'CGCCTCCGTTGACATTGATTTT3' & & \\
\hline & AJ223497 & PEPC & Phosphoenolpyruvate carboxylase & F:5'GGTTGGGTTTATTGGTTTGTTTATG3' & 134 & 0.934 \\
\hline & & & & R:5'ATTCCCTTGCTCGGTTTTGTTA3' & & \\
\hline & A)27II 62 & AGPase & $\begin{array}{l}\text { ADP-glucose pyrophosphorylase } \\
\text { small subunit }\end{array}$ & F:5'AGACACCACCACCCCGTTTGAC3' & 129 & 0.974 \\
\hline & & & & R:5' TTTAGGGATAAGGCAGGAGGAT3' & & \\
\hline & AB04I622 & BcRK6 & Receptor kinase 6 & F:5'AGGTTAAGTGACGGGCAAGAAA3' & 143 & 1.019 \\
\hline & & & & R:5'TTGAACGCAACAGCCAAGAAGT3' & & \\
\hline & AY065839 & SUCl & Sucrose transporter & F:5'GCCAAGGACTGTCGTTAGGAGTTT3' & 133 & 0.970 \\
\hline & & & & R:5'TGCGATTGCTCCGACTATAAATG3' & & \\
\hline
\end{tabular}


included to standardize each reaction run with respect to RNA integrity, sample loading and inter-PCR variations $[61,62]$.

The CT values recorded in the Opticon Monitor 2.0 (MJ Research) were downloaded and processed in EXCEL. The mean CT value for each gene was calculated from three replicates and used for further calculations of the Transcript Level (TL) using the following formula [60]:

$\mathrm{TL}=\left(\mathrm{E}_{\text {ref }}+1\right)^{\text {CTsample }} /\left(\mathrm{E}_{\text {target }}+1\right)^{\mathrm{CTsample}} \div\left(\mathrm{E}_{\text {ref }}+1\right)^{\text {CTcalibrator }} /\left(\mathrm{E}_{\text {target }}+1\right)^{\text {CTcalibrator }}$

in which $E_{\text {ref }}$ is the PCR efficiency of the control gene $\beta$ actin, $\mathrm{E}_{\text {target }}$ is the PCR efficiency of the gene under study, $\mathrm{CT}_{\text {ref }}$ is the CT value of the control gene $\beta$-actin, and $\mathrm{CT}_{\text {target }}$ is the CT value of the gene under study. The TL value determined by this formula represents a relative abundance of the transcripted copy number of a gene and allows us to make comparisons between the transcript abundances for different genes and between two cultivars for a specific gene.

\section{GC Analysis}

The dissected seeds were dried by refrigeration until their weight remained constant and then the dried seeds were weighed and finely ground in tubes. After dissolution in 1 $\mathrm{mL}$ petroleum ether/aether $(\mathrm{v} / \mathrm{v}=1: 1)$, each sample was saponified in $1 \mathrm{~mL} 0.4 \mathrm{~N}$ methanolic-KOH $(10 \%(\mathrm{w} / \mathrm{v})$ $\mathrm{KOH}, 5 \%(\mathrm{v} / \mathrm{v}) \mathrm{H}_{2} \mathrm{O}$ in methanol) at $60^{\circ} \mathrm{C}$ for $1 \mathrm{~h}$. After saponification, samples were cooled on ice and added to

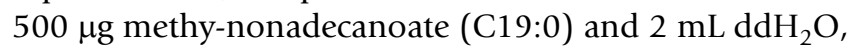
and vortexed. After centrifugation, the supernatant was analyzed by GC (Gas Chromatograph).

GC analysis was performed with a gas chromatogram (Agilent $5890 \mathrm{~N}$ ) fitted with a $30 \mathrm{~m}$ FFAP capillary column (ID $0.25 \mathrm{~mm}$ narrow bore and film thickness $0.5 \mu \mathrm{m}$ ). The GC conditions were set as follows: injection volume, $1 \mu \mathrm{L}$; injector temperature and flame ionization detector temperature, $260^{\circ} \mathrm{C}$; carrier gas, nitrogen at a split vent ratio of $50: 1$; column head pressure, $172.7 \mathrm{kPa}$ (25 psi) to make up a total flow of $78.2 \mathrm{~mL} / \mathrm{min}$ and a column flow of $1.5 \mathrm{~mL} / \mathrm{min}$ (average velocity, $42 \mathrm{~cm} / \mathrm{s}$ ); hydrogen flow, $40 \mathrm{~mL} / \mathrm{min}$; air flow, $400 \mathrm{~mL} / \mathrm{min}$; running temperature program, $160^{\circ} \mathrm{C}$ for $1 \mathrm{~min}$, and then increased $4^{\circ} \mathrm{C}$ per min to $240^{\circ} \mathrm{C}$ and held at this temperature for $10 \mathrm{~min}$.

The result of GC analysis is displayed by its absolute value and relative value. The absolute value and relative value were calculated by

$$
\begin{gathered}
\omega_{\mathrm{i}}=\mathrm{A}_{\mathrm{i}} \times \mathrm{m}_{\mathrm{s}} /\left(\mathrm{A}_{\mathrm{s}} \times \mathrm{m}\right) \\
\text { and }(\%)=\mathrm{A}_{\mathrm{i}} / \sum \mathrm{A}_{\mathrm{i}} \times 100
\end{gathered}
$$

where $A_{i}$ is the area of the fatty acid peak, $A_{s}$ is the area of the control peak, $m_{s}$ is the mass quantity of the control, and $\mathrm{m}$ is the dry weight of the sample. Every sample was analyzed three times. The average value and standard deviation were calculated for each sample.

\section{Statistical Analysis}

As shown in Table 2, the mean (Mean TL), coefficient of variation (C.V. of TL) and relative value of the transcript levels (RTL) were determined in order to characterize the transcript abundance of the 32 genes in study over time.

The mean transcript level (Mean TL) for each gene was calculated as an average of 8 stages from 10 to 45 DAP, and the relative transcript level (RTL) was calculated as the mean transcript level of the gene divided by the sum of the mean transcript levels of 32 genes and expressed as a percentage. The coefficient of variation (C.V. of TL) was expressed as the standard deviation as a percentage of the mean to measure the variation in transcript abundance of a gene during the time course.

A correlation analysis was made between the fatty acid accumulation pattern and the transcript level time course for each gene using the software embedded in EXCEL (Table 3).

\section{Competing interests}

The authors declare that they have no competing interests.

\section{Authors' contributions}

CML conceived the study and edited the manuscript. YPH performed experiments and analyses and wrote the manuscript. GW and XDL performed validating experiments and analyses. YLC, YHW and LX contributed to the writing of the manuscript and to the experimental design. All authors read and approved the final manuscript.

\section{Acknowledgements}

This work was financially supported by the Development Plan of the State Key Fundamental Research of China (2006CBI0 1600), and by the National High Technology and Development Program of China (2008AAI0ZI52).

\section{References}

I. Liu Z, Yang X, Fu Y, Zhang Y, Yan J, Song T, Rocheford T, Li J: Proteomic analysis of early germs with high-oil and normal inbred lines in maize. Mol Biol Rep 2009, 36(4):8। 3-82I.

2. Dong J, Keller WA, Yan W, Georges F: Gene expression at early stages of Brassica napus seed development as revealed by transcript profiling of seed-abundant cDNAs. Planta 2004, 218(3):483-49।.

3. Parcy F, Valon C, Raynal M, Gaubier-Comella P, Delseny M, Giraudat $\mathrm{J}$ : Regulation of gene expression programs during Arabidopsis seed development: roles of the $A B I 3$ locus and of endogenous abscisic acid. Plant Cell 1994, 6( I I): I567-I582.

4. Ke J, Behal RH, Back SL, Nikolau BJ, Wurtele ES, Oliver DJ: The role of pyruvate dehydrogenase and acetyl-coenzyme A synthetase in fatty acid synthesis in developing Arabidopsis seeds. Plant Physiol 2000, I 23(2):497-508. 
5. Ruuska SA, Girke T, Benning C, Ohlrogge JB: Contrapuntal networks of gene expression during Arabidopsis seed filling. Plant Cell 2002, I 4(6): I I9I-I 206.

6. Cernac A, Benning C: WRINKLEDI encodes an AP2/EREB domain protein involved in the control of storage compound biosynthesis in Arabidopsis. Plant J 2004, 40(4):575-585.

7. Mekhedov S, de IO, Ohlrogge J: Toward a functional catalog of the plant genome. A survey of genes for lipid biosynthesis. Plant Physiol 2000, I 22(2):389-402.

8. Beisson F, Koo AJ, Ruuska S, Schwender J, Pollard M, Thelen JJ, Paddock T, Salas J], Savage L, Milcamps A, et al.: Arabidopsis genes involved in acyl lipid metabolism. A 2003 census of the candidates, a study of the distribution of expressed sequence tags in organs, and a web-based database. Plant Physiol 2003, I 32(2):68|-697.

9. Ohdan T, Francisco PB, Sawada T, Hirose T, Terao T, Satoh H, Nakamura $Y$ : Expression profiling of genes involved in starch synthesis in sink and source organs of rice. J Exp Bot 2005 56(422):3229-3244.

10. Hills MJ: Control of storage-product synthesis in seeds. Curr Opin Plant Biol 2004, 7(3):302-308.

II. Sasaki Y, Nagano Y: Plant acetyl-CoA carboxylase: structure, biosynthesis, regulation, and gene manipulation for plant breeding. Biosci Biotechnol Biochem 2004, 68(6): I I75- I I84.

12. Roesler K, Shintani D, Savage L, Boddupalli S, Ohlrogge J: Targeting of the Arabidopsis homomeric acetyl-coenzyme A carboxylase to plastids of rapeseeds. Plant Physiol 1997, I I 3(I):75-8I.

13. Shintani D, Roesler K, Shorrosh B, Savage L, Ohlrogge J: Antisense expression and overexpression of biotin carboxylase in tobacco leaves. Plant Physiol I 997, I I 4(3):88 I-886.

14. Thelen J], Mekhedov S, Ohlrogge JB: Brassicaceae express multiple isoforms of biotin carboxyl carrier protein in a tissue-specific manner. Plant Physiol 200I, I 25(4):2016-2028.

15. Elborough KM, Swinhoe R, Winz R, Kroon JT, Farnsworth L, Fawcett T, Martinez-Rivas JM, Slabas AR: Isolation of cDNAs from Brassica napus encoding the biotin-binding and transcarboxylase domains of acetyl-CoA carboxylase: assignment of the domain structure in a full-length Arabidopsis thaliana genomic clone. Biochem J 1994, 30 I (Pt 2):599-605.

16. Roesler KR, Shorrosh BS, Ohlrogge JB: Structure and expression of an Arabidopsis acetyl-coenzyme A carboxylase gene. Plant Physiol 1994, I05(2):6 I I-6I7.

17. Simon JW, Slabas AR: cDNA cloning of Brassica napus malonylCoA:ACP transacylase (MCAT) (fab D) and complementation of an E. coli MCAT mutant. FEBS Lett 1998, 435(23):204-206.

18. Dehesh K, Tai H, Edwards P, Byrne J, Jaworski JG: Overexpression of 3-ketoacyl-acyl-carrier protein synthase IIIs in plants reduces the rate of lipid synthesis. Plant Physiol 200I, | 25(2): I |03-II| 4.

19. Yasuno R, von WK, Wada H: Identification and molecular characterization of the beta-ketoacyl-[acyl carrier protein] synthase component of the Arabidopsis mitochondrial fatty acid synthase. J Biol Chem 2004, 279(9):8242-825I.

20. Carlsson AS, LaBrie ST, Kinney A], von WK, Browse J: A KAS2 cDNA complements the phenotypes of the Arabidopsis fab I mutant that differs in a single residue bordering the substrate binding pocket. Plant J 2002, 29(6):76I-770.

21. Lindqvist Y, Huang W, Schneider G, Shanklin J: Crystal structure of delta9 stearoyl-acyl carrier protein desaturase from castor seed and its relationship to other di-iron proteins. EMBO J 1996, I 5(16):408I-4092.

22. Han J, Luhs W, Sonntag K, Zahringer U, Borchardt DS, Wolter FP, Heinz E, Frentzen M: Functional characterization of betaketoacyl-CoA synthase genes from Brassica napus $L$. Plant $M o l$ Biol 200I, 46(2):229-239.

23. Puyaubert J, Dieryck W, Costaglioli P, Chevalier S, Breton A, Lessire $\mathrm{R}$ : Temporal gene expression of 3-ketoacyl-CoA reductase is different in high and in low erucic acid Brassica napus cultivars during seed development. Biochim Biophys Acta 2005, 1687(I-3): $152-163$

24. Heath RJ, Rock CO: Roles of the FabA and FabZ beta-hydroxyacyl-acyl carrier protein dehydratases in Escherichia coli fatty acid biosynthesis. J Biol Chem I996, 27 I(44):27795-2780 I.
25. Rossak M, Smith M, Kunst L: Expression of the FAEI gene and FAEI promoter activity in developing seeds of Arabidopsis thaliana. Plant Mol Biol 200I, 46(6):717-725.

26. Wu G, Wu Y, Xiao L, Li X, Lu C: Zero erucic acid trait of rapeseed (Brassica napus $L$.) results from a deletion of four base pairs in the fatty acid elongase I gene. Theor Appl Genet 2008, I I 6(4):49|-499.

27. Okuley J, Lightner J, Feldmann K, Yadav N, Lark E, Browse J: Arabidopsis FAD2 gene encodes the enzyme that is essential for polyunsaturated lipid synthesis. Plant Cell 1994, 6(I): I47-I58.

28. Hitz WD, Carlson TJ, Booth JR, Kinney AJ, Stecca KL, Yadav NS: Cloning of a higher-plant plastid omega-6 fatty acid desaturase cDNA and its expression in a cyanobacterium. Plant Physiol 1994, I 05(2):635-64I

29. Reed DW, Schafer UA, Covello PS: Characterization of the Brassica napus extraplastidial linoleate desaturase by expression in Saccharomyces cerevisiae. Plant Physiol 2000 , I 22(3):715-720.

30. Iba K, Gibson S, Nishiuchi T, Fuse T, Nishimura M, Arondel V, Hugly S, Somerville C: A gene encoding a chloroplast omega-3 fatty acid desaturase complements alterations in fatty acid desaturation and chloroplast copy number of the fad7 mutant of Arabidopsis thaliana. I Biol Chem 1993, 268(32):24099-24I 05.

31. Salas JJ, Ohlrogge JB: Characterization of substrate specificity of plant FatA and FatB acyl-ACP thioesterases. Arch Biochem Biophys 2002, 403(I):25-34.

32. Mandal MN, Santha IM, Lodha ML, Mehta SL: Cloning of acyl-acyl carrier protein (ACP) thioesterase gene from Brassica juncea. Biochem Soc Trans 2000, 28(6):967-969.

33. Dormann P, Voelker TA, Ohlrogge JB: Accumulation of palmitate in Arabidopsis mediated by the acyl-acyl carrier protein thioesterase FATB I. Plant Physiol 2000, I 23(2):637-644.

34. Jain RK, Coffey M, Lai K, Kumar A, MacKenzie SL: Enhancement of seed oil content by expression of glycerol-3-phosphate acyltransferase genes. Biochem Soc Trans 2000, 28(6):958-96I.

35. Bourgis F, Kader JC, Barret P, Renard M, Robinson D, Robinson C, Delseny M, Roscoe T]: A plastidial lysophosphatidic acid acyltransferase from oilseed rape. Plant Physiol 1999, I 20(3):913-922.

36. Jako C, Kumar A, Wei Y, Zou J, Barton DL, Giblin EM, Covello PS, Taylor DC: Seed-specific over-expression of an Arabidopsis cDNA encoding a diacylglycerol acyltransferase enhances seed oil content and seed weight. Plant Physiol 200I, I 26(2):86|-874.

37. Rodin J, Ericson ML, Josefsson LG, Rask L: Characterization of a cDNA clone encoding a Brassica napus $12 \mathrm{~S}$ protein (cruciferin) subunit. Relationship between precursors and mature chains. J Biol Chem 1990, 265(5):2720-2723.

38. Ericson ML, Rodin J, Lenman M, Glimelius K, Josefsson LG, Rask L: Structure of the rapeseed $1.7 \mathrm{~S}$ storage protein, napin, and its precursor. J Biol Chem I986, 26 I(3I): | 4576-|458I.

39. Naested H, Frandsen GI, Jauh GY, Hernandez-Pinzon I, Nielsen HB, Murphy DJ, Rogers JC, Mundy J: Caleosins: Ca2+-binding proteins associated with lipid bodies. Plant Mol Biol 2000, 44(4):463-476.

40. Poxleitner M, Rogers SW, Lacey SA, Browse J, Rogers JC: A role for caleosin in degradation of oil-body storage lipid during seed germination. Plant J 2006, 47(6):917-933.

4I. Wang TW, Balsamo RA, Ratnayake C, Platt KA, Ting JT, Huang AH Identification, subcellular localization, and developmental studies of oleosins in the anther of Brassica napus. Plant J 1997, I I (3):475-487.

42. Delisle AJ, Crouch ML: Seed Storage Protein Transcription and mRNA Levels in Brassica napus during Development and in Response to Exogenous Abscisic Acid. Plant Physiol 1989, 9I(2):6I7-623.

43. Hoglund AS, Rodin J, Larsson E, Rask L: Distribution of Napin and Cruciferin in Developing Rape Seed Embryos. Plant Physiol 1992, 98(2):509-515.

44. Huang AH: Oil Bodies and Oleosins in Seeds. Annual Review of Plant Physiology and Plant Molecular Biology 1992, 43(1): 177-200.

45. Murphy DJ, Hernendez-Pinzon I, Patel K, Hope RG, McLauchlan J: New insights into the mechanisms of lipid-body biogenesis in plants and other organisms. Biochem Soc Trans 2000, 28(6):7|0-7||. 
46. Rolletschek H, Borisjuk L, Radchuk R, Miranda M, Heim U, Wobus U, Weber H: Seed-specific expression of a bacterial phosphoenolpyruvate carboxylase in Vicia narbonensis increases protein content and improves carbon economy. Plant Biotechnol J 2004, 2(3):2II-2I9.

47. Klaus D, Ohlrogge JB, Neuhaus HE, Dormann P: Increased fatty acid production in potato by engineering of acetyl-CoA carboxylase. Planta 2004, 219(3):389-396.

48. Mietkiewska E, Brost JM, Giblin EM, Barton DL, Taylor DC: Cloning and functional characterization of the fatty acid elongase (FAEI) gene from high erucic Crambe abyssinica cv. Prophet. Plant Biotechnol J 2007, 5(5):636-645.

49. Puyaubert J, Garbay B, Costaglioli P, Dieryck W, Roscoe TJ, Renard $M$, Cassagne $C$, Lessire R: Acyl-CoA elongase expression during seed development in Brassica napus. Biochim Biophys Acta 2001, 1533(2): $14 \mid-152$.

50. Holbrook LA, van RG, Wilen RW, Moloney MM: Oilbody Proteins in Microspore-Derived Embryos of Brassica napus: Hormonal, Osmotic, and Developmental Regulation of Synthesis. Plant Physiol I 99I, 97(3): I05I-1058.

5I. Finkelstein RR, Somerville CR: Three Classes of Abscisic Acid (ABA)-Insensitive Mutations of Arabidopsis Define Genes that Control Overlapping Subsets of ABA Responses. Plant Physiol 1990, 94(3): I 172-1179.

52. Zou J, Abrams GD, Barton DL, Taylor DC, Pomeroy MK, Abrams SR: Induction of Lipid and Oleosin Biosynthesis by (+)-Abscisic Acid and Its Metabolites in Microspore-Derived Embryos of Brassica napus L. cv Reston (Biological Responses in the Presence of 8[prime]-Hydroxyabscisic Acid). Plant Physiol 1995, 108(2):563-57|.

53. Qi Q, Rose PA, Abrams GD, Taylor DC, Abrams SR, Cutler AJ: (+)Abscisic acid metabolism, 3-ketoacyl-coenzyme A synthase gene expression, and very-long-chain monounsaturated fatty acid biosynthesis in brassica napus embryos. Plant Physiol 1998, II 7(3):979-987.

54. Olesen C, Thomsen KK, Svendsen I, Brandt A: The glyoxysomal 3. ketoacyl-CoA thiolase precursor from Brassica napus has enzymatic activity when synthesized in Escherichia coli. FEBS Lett 1997, 4I 2(I): | 38-140.

55. Katayoon D: How can we genetically engineer oilseed crops to produce high levels of medium-chain fatty acids? Eur J Lipid Sc Tech 200I, I 03(1 0):688-697.

56. Slabas $A R$, White $A, O P$, Fawcett $T$ : Investigations into the regulation of lipid biosynthesis in Brassica napus using antisense down-regulation. Biochem Soc Trans 2002, 30(Pt 6): 1056-1059.

57. Kai N, Suzuki G, Watanabe M, Isogai A, Hinata K: Sequence comparisons among dispersed members of the Brassica $\mathbf{S}$ multigene family in an $\mathbf{S 9}$ genome. Mol Genet Genomics 200I, 265(3):526-534

58. Ohlrogge J, Browse J: Lipid biosynthesis. Plant Cell 1995, 7(7):957-970.

59. Vicient CM, Delseny M: Isolation of total RNA from Arabidopsis thaliana seeds. Anal Biochem 1999, 268(2):4I2-4I3.

60. Pfaffl MW: A new mathematical model for relative quantification in real-time RT-PCR. Nucleic Acids Res 200I, 29(9):e45

6I. Czechowski T, Stitt M, Altmann T, Udvardi MK, Scheible WR Genome-wide identification and testing of superior reference genes for transcript normalization in Arabidopsis. Plant Physiol 2005, 139(I):5-17.

62. Vandesompele J, De PK, Pattyn F, Poppe B, Van RN, De PA, Speleman $F$ : Accurate normalization of real-time quantitative RT-PCR data by geometric averaging of multiple internal control genes. Genome Biol 2002, 3(7):RESEARCH0034.
Publish with Bio Med Central and every scientist can read your work free of charge

"BioMed Central will be the most significant development for disseminating the results of biomedical research in our lifetime. "

Sir Paul Nurse, Cancer Research UK

Your research papers will be:

- available free of charge to the entire biomedical community

- peer reviewed and published immediately upon acceptance

- cited in PubMed and archived on PubMed Central

- yours - you keep the copyright
BioMedcentral 